\title{
Assessing Ecosystem Services Supply-Demand (Mis)Matches for Differential City Management in the Yangtze River Delta Urban Agglomeration
}

\author{
Wenbo Cai ${ }^{1,2}$, Wei Jiang ${ }^{2}$ D, Hongyu Du ${ }^{3}$, Ruishan Chen ${ }^{1}$ and Yongli Cai ${ }^{1, *(D)}$ \\ 1 School of Design \& China Institute for Urban Governance, Shanghai Jiao Tong University, \\ 800 Dongchuan Rd., Minhang District, Shanghai 200240, China; wbcai@rcees.ac.cn (W.C.); \\ chenrsh04@gmail.com (R.C.) \\ 2 Research Center for Eco-Environment Sciences, State Key Laboratory of Urban and Regional Ecology, Chinese \\ Academy of Sciences, Shuangqing Rd. 18, Beijing 100085, China; weijiang@rcees.ac.cn \\ 3 Institute of Ecology and Sustainable Development, Shanghai Academy of Social Sciences, No.7, Lane 622, \\ Huaihaizhong Road, Huangpu District, Shanghai 200020, China; duhongyu@sass.org.cn \\ * Correspondence: ylcai2020@sjtu.edu.cn
}

check for updates

Citation: Cai, W.; Jiang, W.; Du, H.; Chen, R.; Cai, Y. Assessing Ecosystem Services Supply-Demand

(Mis)Matches for Differential City Management in the Yangtze River Delta Urban Agglomeration. Int. J. Environ. Res. Public Health 2021, 18, 8130. https://doi.org/ 10.3390/ijerph18158130

Academic Editor: Paul B. Tchounwou

Received: 8 June 2021

Accepted: 28 July 2021

Published: 31 July 2021

Publisher's Note: MDPI stays neutral with regard to jurisdictional claims in published maps and institutional affiliations.

Copyright: (c) 2021 by the authors. Licensee MDPI, Basel, Switzerland. This article is an open access article distributed under the terms and conditions of the Creative Commons Attribution (CC BY) license (https:// creativecommons.org/licenses/by/ $4.0 /)$.

\begin{abstract}
With the global increase in population and urban expansion, the simultaneous rise of social demand and degradation of ecosystems is omnipresent, especially in the urban agglomerations of China. In order to manage environmental problems and match ecosystem supply and social demand, these urban agglomerations promoted regional socio-ecological integration but ignored differential city management during the process of integration. Therefore, it is necessary to design a general framework linking ecosystem supply and social demand to differential city management. In addition, in previous studies, ecosystem services supply-demand amount (mis)match assessment was emphasized, but ecosystem services supply-demand type (mis)match assessment was ignored, which may lead to biased decisions. To deal with these problems, this study presented a general ecosystem services framework with six core steps for differential city management and developed a doubleindices (amount and type) method to identify ecosystem services supply-demand (mis)matches in an urban agglomeration. This framework and the double-indices method were applied in the case study of the Yangtze River Delta Urban Agglomeration. Ecosystem supply-demand amount and type (mis)match levels and spatial pattern of twenty-six cities were identified. Twenty-six cities in the YRDUA were classified into five kinds of cities with different levels of ES supply-demand (mis)matches for RS, three kinds of cities for PS, and four kinds of cities for CS. Differential city management strategies were designed. Despite its limitations, this study can be a reference to giving insights into ES supply-demand (mis)match assessment and management.
\end{abstract}

Keywords: ecosystem services; supply-demand (mis)matches; urban governance; urbanization; land use; regional sustainable development

\section{Introduction}

With the global increase in population and urban expansion, the simultaneous rise of social demand and degradation of ecosystems is omnipresent [1-3], especially in urban agglomerations of China. China's reform and opening up accelerated the speed of urbanization, which led to several urban agglomerations such as the Yangtze River Delta Urban Agglomeration (YRDUA), the Pearl River Delta Urban Agglomeration (PRDUA), and the Beijing-Tianjin-Hebei Urban Agglomeration (BTHUA). In these urban agglomerations, the rapid economic development and urban expansion have exacerbated the conflict between construction land and ecological land, leading to serious ecological and environmental problems (e.g., air and water pollution, soil erosion, biodiversity loss) in administrative areas and across administrative areas [4,5]. At the same time, with the improvement of the living standards of urban residents and population growth [3], demands for ecosystem 
services (ES) have been largely increased in these urban agglomerations, resulting in mismatches of ES supply and demand in cities. To manage environmental problems and to match ecosystem supply and social demand, these urban agglomerations promoted socioecological integration and carried out the regional unified city management. However, due to different ecological backgrounds, economic development, and population size, regional unified city management may not be that effective. Therefore, it is necessary to carry out differential city management for cities in these urban agglomerations.

Ecosystem services supply-demand (mis)match assessment may have a great potential in differential land use management [6-8]. Ecosystem services (ES) can be defined as direct and indirect contributions to human well-being that originate from ecosystems [9]. ES supply refers to the capacity of a particular area to provide a specific bundle of ecosystem goods and services within a given time period [10]. ES demand was described as the consumption or use of ES in a specific area within a given time period [11] or the preference or expectation level of human society or individuals for the specific attributes of ecosystem services [12]. ES supply-demand (mis)match are defined as the differences in quality or quantity that occur between ES supply and demand in an ecosystem unit or in a specific area [13]. The potential of the different land covers for supplying multiple ES may be the result of biophysical factors or anthropogenic actives, which need certain management to meet people's demands $[14,15]$. Therefore, land covers can be classified into three categories, including deficit, stable, and surplus areas of ES [14,15]. Based on ES supply-demand (mis)match assessment with land covers of a city, the differences in ES supply and demand among cities can be identified, and thus cities can be classified. Then, differential city management countermeasures may be proposed by combining an influential factors analysis.

It is necessary to establish comparable methods for ES supply assessment and ES demand assessment. Previous studies mostly focused on the ES supply-side assessment [16-18]. Due to the growth of social demand for ES, scholars began to pay attention to ES demand assessment $[12,19,20]$. In recent studies, comparable ES supply-demand assessment methods have appeared [21,22]. ES supply-demand assessments can be performed by participatory methods [23,24], modeling [25,26], and mapping [27,28]. Modeling was a good choice for quantitative assessments in a data-rich region $[25,26]$, while participatory methods have succeeded in ES supply-demand studies with a combination of mapping methods in a data-scarce region [6,29]. For example, Burkhard et al. [10] developed an ES supplydemand land use matrix based on the participatory mapping. Such a method linking the ES supply-demand assessment to land cover will promote land use management at a regional scale $[6,10,11]$. Successful cases can be found in regional-scale studies, e.g., assessment of recreational service supply and demand in the Basque Country in Spain [30], and ES supplydemand amount indices for the spatiotemporal analysis at watershed scale in China [31]. Both ES supply and demand can be assessed and visualized by relative comparable units or rates [12]. In addition, in previous studies, the ES supply-demand amount (mis)match assessment was emphasized, but the ES supply-demand type (mis)match assessment was ignored, which may lead to biased decisions [22,32-34]. However, the ES supply-demand amount (mis)match assessment could only show the one-side information of the overall status ES supply and demand of a study area, while the ES supply-demand type (mis)match assessment could provide the other-side information in decision making $[15,35]$. Therefore, the overall assessment should be performed by combing ES supply-demand amount and type match. However, up until present, few studies addressed on both amount and types of ES supply-demand matches for decision making.

The Yangtze River Delta Urban Agglomeration (YRDUA) has large spatial heterogeneity in the ecological background of northern and southern areas. It made great progress in rapid urbanization and economic growth during the past forty years, causing environmental problems such as air pollution, water pollution, and arable land loss, thus threatening human well-being and regional sustainable development [15,36-38]. As a typical area of large natural heterogeneity and high intensity of development, YRDUA was selected 
as the study area for ES supply-demand matches assessment. Taking the YRDUA as an example, the objectives of this study are to (1) present an ES framework for differential city management in an urban agglomeration, (2) develop a double-indices method for identification of ES amount and type (mis)matches in a city, and (3) classify cities in the YRDUA for differential city management based on the double-indices method.

\section{Methodology}

Differential city management based on ES supply-demand (mis)match assessment is a complex process in an urban agglomeration. Therefore, we present a general ES framework (Figure 1) for differential city management in an urban agglomeration. This framework comprises six core steps:

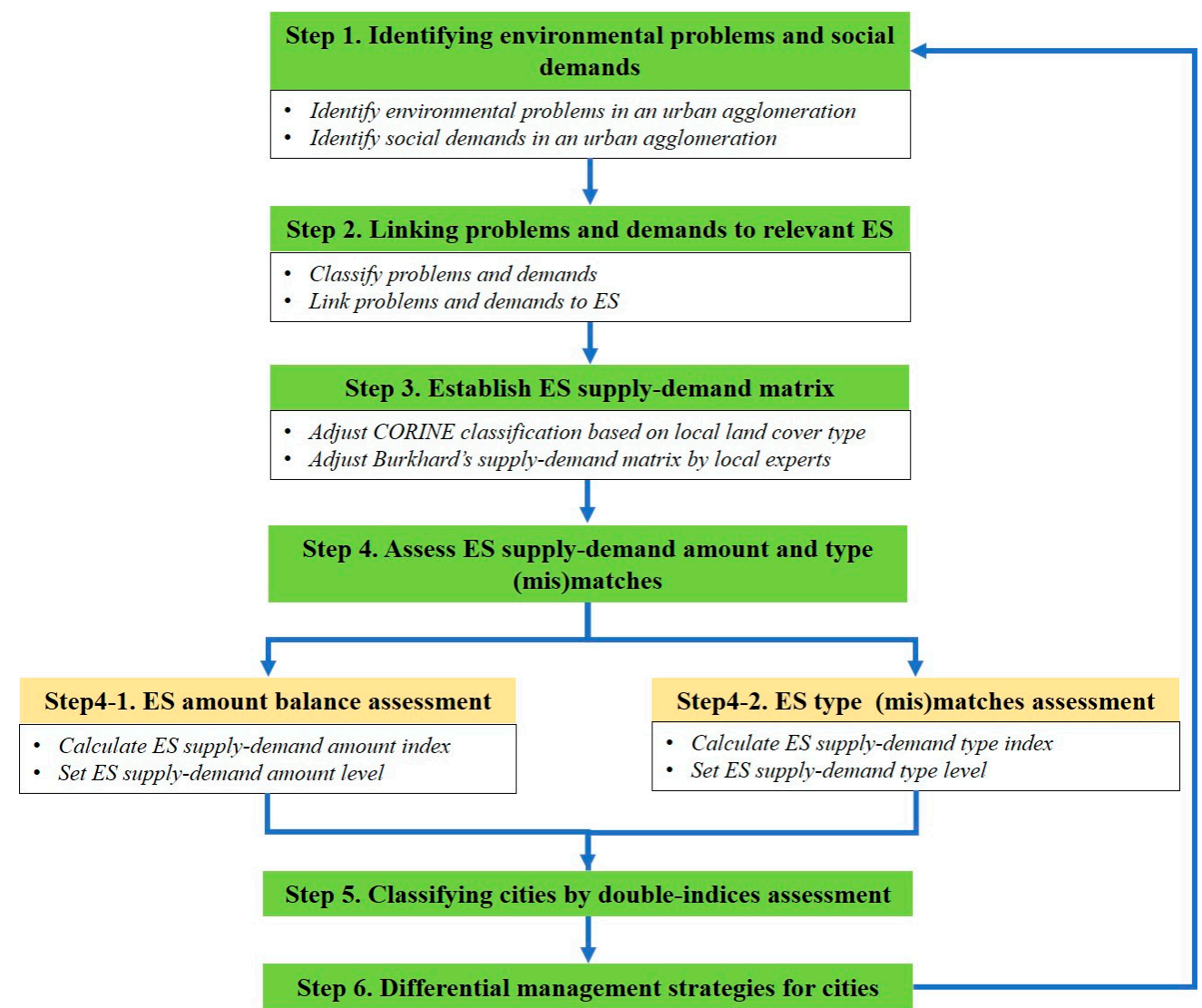

Figure 1. A general ES framework with six core steps for differential city management.

\subsection{Step 1. Identify Environmental Problems and Social Demands}

Identify environmental problems: regional environmental problems (water pollution, air pollution, soil erosion, flooding, and so on) may be identified through a review of government documents, academic reports, news, and combing with expert consultation and field works in an urban agglomeration.

Identify social demands: the demands from the society include materials, e.g., food and spirit, or aesthetics, which can be analyzed by the socio-economic development plan, social media reports, and interviews or surveys in an urban agglomeration.

\subsection{Step 2. Link Problems and Demands to Relevant Ecosystem Services}

Classify problems and demands: environmental problems can be classified based on natural process analysis, e.g., flooding related to the water flow process [39], and human activities analysis, e.g., the air pollution related to pollution emission [40]. Social demands can be classified into two categories: (1) demands for materials, e.g., crops, fresh air, clean 
water, timber, aquaculture, and (2) demands for spirit, e.g., recreation, tourism, aesthetic, cultural heritage.

Link problems and demands to ES: Based on supply-demand coupling analysis, the causal relationship between environmental problems and Regulating Services (RS) can be identified since RS (e.g., air quality regulation, water flow regulation, climate regulation) are closely related to ecological and environmental process [41-43]. Material demands are related to Provisioning Services (PS) [44] since PS was defined as final ecosystem goods to society, e.g., crops provision, freshwater provision. Spiritual demands are related to Cultural Services (CS) $[45,46]$ since CS are closely related to spiritual perception.

\subsection{Step 3. Establish Ecosystem Services Supply-Demand Matrix}

The CORINE (Co-ordinated Information on the Environment) land cover classification based on European context provides a good reference for the land cover classification of other continents [47]. Land cover types in the CORINE classification can be transferred to natural or human-modified ecosystem types that provide or consume ecosystem goods and services $[10,11,47]$. In addition, the CORINE classification should be adjusted according to local land cover types [47].

Burkhard's method constructs an ES matrix combining land cover information in the assessment of ecosystems' capacities to supply ES and demand [10,11]. In the ES supply matrix, natural land cover types (e.g., forest, wetland) are given high capacities scores to provide several ES. In contrast, human-modified land cover types (e.g., urban fabric, industrial, or commercial areas) are given very low or no relevant capacities scores to provide RS and PS. Semi-natural land cover types (e.g., croplands) are often provided high capacities scores in specific PS. In the ES demand matrix, demands scoring for ES were suggested based on population numbers and average consumption patterns but also on land use activities and on their demands for certain services [10,15,48]. Humanmodification land cover types with high population numbers and high human activities had high demands for multiple ecosystem services. Natural and semi-nature land cover types had low or no relevant demands for ES because normally fewer people were present there.

\subsection{Step 4. Assess ES Supply-Demand Amount and Type (Mis)Matches}

2.4.1. Step 4-1. Assess City ES Supply-Demand (Mis)Matches Based on the ES Amount Index

According to previous studies of ES supply-demand index [15,31], we defined the ES Supply-demand Amount Index (ESAI) [15,31], which links the actual supply of the ecosystem with the demand of human beings, was employed to reveal ES supply-demand balance of single ES for each pixel in this study (Equation (1)):

$$
\mathrm{ESAI}=\frac{(\mathrm{S}-\mathrm{D})}{(\operatorname{Smax}+\text { Dmax }) / 2}
$$

where S and D, respectively, refer to specific actual supply and demand; Smax and Dmax, respectively, represent the maximum supply and human demand of specific ES extracted from the corresponding $S$ and $D$ space layers. This study provided the explanation that ESAI indicates the ES supply-demand status based on studies of [15,31]:

ESAI $>0$ indicates that the ES supply meets the demand, i.e., there is surplus;

$\mathrm{ESAI}=0$, indicating ES supply and demand balance;

$\mathrm{ESAI}<0$ indicates that supply does not meet demand, i.e., there is a deficit.

Mean of amount index: Mean was employed to calculate the balance of multiple ES [15,31]. It is calculated as the arithmetic mean of ESAI of each category of ES

$$
\text { Mean }=\frac{1}{n} \sum_{\mathrm{i}=1}^{n} \text { ESARi }
$$


where $n$ is the number of estimated ES and Mean is the supply-demand index for each ES type.

Sum of amount index: Sum was defined to calculate the sum of the total amount of ESAI of each administrative unit (Equation (3)):

$$
\text { Sum }=\sum_{1}^{n}(S n-D n) * j
$$

where $S n$ and $D n$, respectively, refer to the specific actual supply and demand of each ES, $n$ refers to the number of ES, $j$ refers to the number of pixels in each administrative unit. It was then possible to calculate indices by coding the index using the 'spatial calculation' module in ArcGIS.

2.4.2. Step 4-2. Assess City ES Supply-Demand (Mis)Matches Based on the ES Type Index

Previous studies, e.g., ES supply-demand budget [11], modified ES supply-demand balance index [36] and arithmetic mean of it $[15,31]$ and made the comparison of the amount of ES supply and demand balance [12].

Based on previous studies, we addressed the importance of matches in various types of multiple ES supply and demand for urban land use management and introduced the ES Supply-demand Type Index (ESTI) for evaluating (mis)matches of ES supplydemand types.

$$
\text { ESTI }=\frac{[\mathrm{N}(\text { surpuls })+\mathrm{N}(\text { balance })]-\mathrm{N}(\text { deficit })}{\mathrm{N}(\text { surplus, balance, deficit })}
$$

Among them, $\mathrm{N}$ (surplus) indicates the number of ES that ESAI $>0$; $\mathrm{N}$ (balance) indicates the number of ES that ESAI $=0$; $\mathrm{N}$ (deficit) indicates the number of $\mathrm{ES}$ that ESDB $<0 . N$ (total) represents the total number ES that ESAI $>0 /=0 /<0$. This study gave the explanation of ESTI based on [15,31]:

If ESTI > 0, in the total number of ES, the number of highly matched (positive) and matched (zero) ESs is more than the number of imbalanced (negative). The higher the value, the higher the ES supply-demand matches from the perspective of the number of ES.

If $\mathrm{ESTI}=0$, in the total number of ES, the number of highly matched (positive) and matched (zero) ES is equal to the number of imbalanced (negative), indicating that the supply and demand match exactly.

If ESTI $<0$, in the total number of ES, the number of highly matched (positive) and matched (zero) ES is less than the number of imbalanced (negative). The lower the value is, the lower the ES supply-demand from the perspective of the number of ES.

\subsubsection{Step 4-3. Rating ES Supply-Demand (Mis)Matches}

We classified five levels of multiple ES supply-demand balance of each administrative unit according to amount matches (mean and sum) and type matches (Table 1).

Table 1. Five level of amount index and type index.

\begin{tabular}{ccc}
\hline Level & Meaning & Range \\
\hline I & High Match & $0.5 \leq$ Amount $/$ Type $\leq 1.0$ \\
II & Medium Match & $0.1 \leq$ Amount $/$ Type $<0.5$ \\
III & Match & $-0.1<$ Amount $/$ Type $<0.1$ \\
IV & Medium Mismatch & $-0.5<$ Amount $/$ Type $<-0.1$ \\
V & High Mismatch & $-1.0 \leq$ Amount $/$ Type $\leq-0.5$ \\
\hline
\end{tabular}

Burkhard et al. 2014 suggested using equal intervals to classify ES supply, demand, and supply-demand matches [10]. In the first step, we used an equal interval of 0.5 to define different levels for ES supply-demand matches. Then, we defined $-0.1 \sim 0.1$ as an interval of the match since local experts considered that it was nearly impossible that ES 
supply was exactly equal to demand in the real world. The details of the five levels of multiple ES are presented in Table 1.

Thus, five levels of quantity and type in multiple ES were divided: I indicates that the ES supply highly exceeds demand (high match); II indicates that the ES supply exceeds demand (medium match); III indicates that ES supply is relatively equal to demand (match); IV indicates that ES does not meet demand (medium mismatch); $\mathrm{V}$ indicates that ES demand highly exceeds supply (high mismatch).

\subsection{Step 5. Classify Cities by Double-Indices Assessment}

Cities can be classified by double-indices assessment of amount matches and type matches (Figure 1). Based on five different levels of ESAI and ESTI, twenty-five $(5 \times 5)$ potential types can be defined totally (Figure 2), i.e., medium mismatch and medium match of ESAI and ESTI.

\begin{tabular}{|c|c|c|c|c|}
\hline $\begin{array}{l}\text { High Match- } \\
\text { High Match }\end{array}$ & $\begin{array}{l}\text { High Match- } \\
\text { Medium Match }\end{array}$ & $\begin{array}{c}\text { High Match- } \\
\text { Match }\end{array}$ & $\begin{array}{l}\text { High Match- } \\
\text { Medium } \\
\text { Mismatch }\end{array}$ & $\begin{array}{l}\text { High Match- } \\
\text { High Mismatch }\end{array}$ \\
\hline $\begin{array}{c}\text { Medium } \\
\text { Match-High } \\
\text { Match }\end{array}$ & $\begin{array}{l}\text { Medium Match- } \\
\text { Medium Match }\end{array}$ & $\begin{array}{l}\text { Medium } \\
\text { Match- } \\
\text { Match }\end{array}$ & $\begin{array}{l}\text { Medium Match- } \\
\text { Medium } \\
\text { Mismatch }\end{array}$ & $\begin{array}{l}\text { Medium Match- } \\
\text { High Mismatch }\end{array}$ \\
\hline $\begin{array}{c}\text { Match-High } \\
\text { Match }\end{array}$ & $\begin{array}{l}\text { Match-Medium } \\
\text { Match }\end{array}$ & $\begin{array}{l}\text { Match- } \\
\text { Match }\end{array}$ & $\begin{array}{c}\text { Match-Medium } \\
\text { Mismatch }\end{array}$ & $\begin{array}{c}\text { Match-High } \\
\text { Mismatch }\end{array}$ \\
\hline $\begin{array}{c}\text { Medium } \\
\text { Mismatch- } \\
\text { High Match }\end{array}$ & $\begin{array}{c}\text { Medium } \\
\text { Mismatch- } \\
\text { Medium Match }\end{array}$ & $\begin{array}{l}\text { Medium } \\
\text { Mismatch- } \\
\text { Match }\end{array}$ & $\begin{array}{l}\text { Medium } \\
\text { Mismatch- } \\
\text { Medium } \\
\text { Mismatch }\end{array}$ & $\begin{array}{c}\text { Medium } \\
\text { Mismatch-High } \\
\text { Mismatch }\end{array}$ \\
\hline $\begin{array}{c}\text { High } \\
\text { Mismatch- } \\
\text { High Match }\end{array}$ & $\begin{array}{l}\text { High Mismatch- } \\
\text { Medium Match }\end{array}$ & $\begin{array}{l}\text { High } \\
\text { Mismatch- } \\
\text { Match }\end{array}$ & $\begin{array}{c}\text { High Mismatch- } \\
\text { Medium } \\
\text { Mismatch }\end{array}$ & $\begin{array}{l}\text { High Mismatch- } \\
\text { High Mismatch }\end{array}$ \\
\hline
\end{tabular}

Figure 2. $5 \times 5$ City Types of ES Supply-demand Amount Index (ESAI) and ES Supply-demand Match Type Index (ESTI).

Sustainable land use management strategies can be put forward to each of the types. Unique types can be identified according to the (mis)matches of amount and type indicators in the specific study area.

\subsection{Step 6. Design Differential Land Use Management Strategies}

Differential land use management can be developed based on the double-indices (mis)matches assessment for three kinds of situations:

(1) For cities with both 'match' in ES amount and type, the ecosystem conservation policy, e.g., Ecological Redland policy, may be suggested for multiple ES surplus conservation, especially for cities with 'high-match, high-match'.

(2) For cities with both 'mismatch' in ES amount and type, urban land control, population control, resource restraint policy for demand restraint may be the main city management policy.

(3) For cities with one 'match' and one 'mismatch', in ES amount and type, controlling the total amount of ES or making more matches of each main type of ES may be considered. 


\section{Case Study}

\subsection{Identify Environmental Problems and Demands}

\subsubsection{Study Area}

The YRDUA accounts for $11.7 \%$ of the national population with $2.14 \%$ of the total land area of China, and its output accounts for about $20 \%$ of total GDP [49,50]. It is one of the regions with the largest economic contribution in China and the highest intensity of human development activities, consumption of various resources and energy, and emission intensity of pollutants. Prior to the release of the Development Plan of the YRDUA (2016-2030), provinces and cities coped with environmental management independently with prominent overlapping, conflicts, and contradictions among the plans. Although the provinces and cities hold a highly accepted attitude towards the integrated supply of ecological products and ES and the integrated layout of environmental infrastructure construction in the YRDUA, it is difficult to achieve in-depth cooperation in actual actions due to the lack of scientific guidance, which restricts the coordinated development of ecological environmental governance and ecological security maintenance in the process of regional urbanization [50].

With the continuous evolution of regional urbanization, a series of ecological and environmental problems have aroused common concern, e.g., air pollution, water pollution [51]. Moreover, urban construction land has occupied many wetlands and arable lands in the recent ten years. Impervious surface area increase leads to the coastal city of waterlogging, surface runoff pollution, urban heat island effect intensifies, and serious eutrophication of Taihu Lake Basin [38].

The YRDUA is located in the lower reaches of the Yangtze River in Eastern China (Figure 3). The northern areas of the YRDUA were occupied by plain areas, while the southern areas were dominated by hills and mountains. The region is mainly located in the subtropical monsoon climate zone with relatively high annual mean temperature $\left(13 \sim 18{ }^{\circ} \mathrm{C}\right)$ and abundant precipitation $(776-2000 \mathrm{~mm})$. The YRDUA covers approximately $206,000 \mathrm{~km}^{2}$, with approximately 147.4 million inhabitants.

In Figure 3 (Right below), there was large spatial heterogeneity in the distribution of land use/land cover in the YRDUA. Paddy fields and rainfed cropland are mainly distributed in the middle and northern plain areas, which occupied $34.69 \%$ and $11.38 \%$ of the total area. In contrast, closed forest land covered most of the southern mountainous areas, which occupied $23.89 \%$ of the region. In addition, urban land and country residential land are concentrated in the middle areas around Taihu Lake and scattered in the northern and southern plain areas. These two types totally accounted for $12.11 \%$ of the total.

Figure 3 (Left below) showed the spatial pattern of the population density of the study area in 2015. High-population-density areas were densely distributed in the middle and eastern areas of the YRDUA. These areas are mainly distributed along with the riverside of the Yangtze River and in the plain area of the Yangtze River Delta. They were mainly located in northern cities, e.g., Shanghai municipality, Suzhou, Wuxi, Changzhou, Yangzhou, Zhenjiang, Nanjing, and Taizhou-J in Jiangsu Province, Heifei and Ma'anshan in Anhui Province, and southern cities, e.g., Hangzhou, Shaoxing, Ningbo and southern areas in Taizhou- $Z$ in Zhejiang Provinces.

There are twenty-five prefecture-level cities and one municipality in the YRDUA, comprising nine cities in Jiangsu Province, eight cities in Zhejiang Province, eight cities in Anhui Province, and Shanghai Municipality (Figure 3). These twenty-six cities were coding by (A1) Hefei, (A2) Anqing, (A3) Chizhou, (A4) Chuzhou, (A5) Ma'anshan, (A6) Tongling, (A7) Wuhu, (A8) Xuancheng in Anhui Province; (J1) Nanjing, (J2) Changzhou, (J3) Nantong, (J4) Suzhou, (J5) Taizhou-J, (J6) Wuxi, (J7)Yancheng, (J8) Yangzhou, (J9) Zhenjiang in Jiangsu Province; (S1) Shanghai Municipality; (Z1) Hangzhou, (Z2) Huzhou, (Z3) Jiaxing, (Z4) Jinhua, (Z5) Ningbo, (Z6) Shaoxing, (Z7) Taizhou-Z, and (Z8) Zhoushan. 


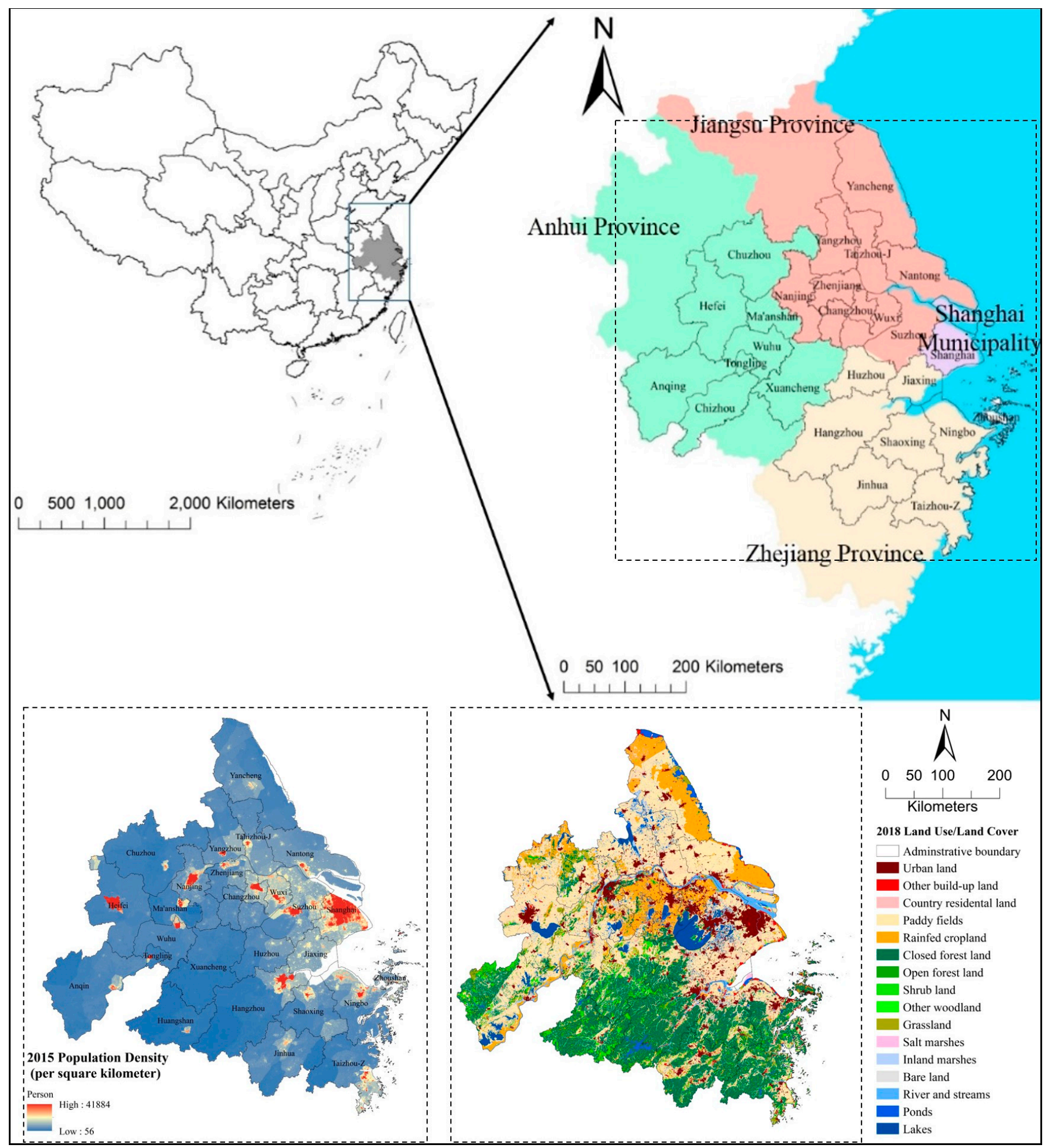

Figure 3. Location, Population Density (Left below), and Land Use (Right below) of Yangtze River Delta Urban Agglomeration.

\subsubsection{Identify Environmental Problems and Demands}

Identify environmental problems: major environmental problems (flooding [52], water shortage [53], air pollution [15], greenhouse effect [54]) were identified for the YRDUA through government documents, environmental reports, and a review of the academic literature (Table 2): two national-level regional plan, one environmental report related to natural disasters and risk assessment, six watershed-level environmental reports related to flooding problems, a watershed-level environmental report related to water pollution 
problems, one municipal environmental report related to natural resource endowments, environmental conditions, and a literature review (e.g., [26-30]).

Identify social demands: huge population number and high economic development has generated high demands for comprehensive development in cities of the YRDUA [1,37] High population generated high material demands, e.g., high demands for food and fresh water. Some megacities, such as Shanghai Municipality with over 20 million people [55], needed to transfer material resources (food, water) from other cities to meet local demands. High economic development required high material consumption in industrial cities [56], e.g., high consumption of industrial water resources. In the meantime, spiritual demands are generated with increasing living standards, such as tourism, recreation, and aesthetics. Demands for recreation in urban green parks and tourism in national parks were generated in cities that promote the communication of tourism among cities [57], such as Hangzhou (ecological tourism destination) with cities around [58].

Table 2. Key Government Documents/Environmental Reports and Related Ecosystem Services (After [51]).

\begin{tabular}{|c|c|c|c|c|c|}
\hline Year & Level & Official Document & Social Demands & $\begin{array}{l}\text { Related Ecosystem } \\
\text { Services }\end{array}$ & Reference \\
\hline 2016 & National & $\begin{array}{l}\text { Development Plan of the } \\
\text { Yangtze River Delta Urban } \\
\text { Agglomeration (2016-2030) }\end{array}$ & $\begin{array}{c}\text { Ecological/Environmental } \\
\text { Integration; Resource } \\
\text { Utilization; Cultural } \\
\text { Integration }\end{array}$ & $\begin{array}{l}\text { Regulating Services, e.g., } \\
\text { Global Climate Regulation, } \\
\text { Air Quality Regulation; } \\
\text { Provisioning Services, e.g., } \\
\text { Crops; Cultural Services, } \\
\text { e.g., Recreation \& Tourism, } \\
\text { Knowledge System }\end{array}$ & [59] \\
\hline 2010 & National & $\begin{array}{l}\text { Regional Plan for the } \\
\text { Yangtze River Delta Region } \\
\text { (2009-2020) }\end{array}$ & $\begin{array}{c}\text { Ecological/Environmental } \\
\text { Integration; Resource } \\
\text { Utilization; } \\
\text { Cultural Integration }\end{array}$ & $\begin{array}{l}\text { Regulating Services, e.g., } \\
\text { Air Quality Regulation; } \\
\text { Provisioning Services, e.g., } \\
\text { Freshwater; Cultural } \\
\text { Services, e.g., } \\
\text { Recreation \& Tourism }\end{array}$ & {$[60]$} \\
\hline 2014 & Regional & $\begin{array}{l}\text { Comprehensive Ecological } \\
\text { Risk Prevention: Natural } \\
\text { Disaster Factors and Risk } \\
\text { Assessment in the Yangtze } \\
\text { River Delta Region }\end{array}$ & $\begin{array}{l}\text { Environmental Problem } \\
\text { Solving: Global Warming; } \\
\text { Green Effect; Flooding }\end{array}$ & $\begin{array}{l}\text { Global Climate Regulation; } \\
\text { Local Climate Regulation; } \\
\text { Water Flow Regulation, } \\
\text { Natural Hazard Regulation }\end{array}$ & [61] \\
\hline 2008-2017 & Regional & $\begin{array}{c}\text { The Health Status Report of } \\
\text { Taihu Lake }\end{array}$ & $\begin{array}{c}\text { Environmental Problem } \\
\text { Solving: Flooding; Water } \\
\text { and Soil Loss; } \\
\text { Water Pollution }\end{array}$ & $\begin{array}{c}\text { Water Purification, } \\
\text { Freshwater, Aquaculture }\end{array}$ & [62] \\
\hline 2013-2018 & Regional & $\begin{array}{l}\text { Annual Report of Flood } \\
\text { Control and Typhoon } \\
\text { Prevention in Taihu } \\
\text { Lake Basin }\end{array}$ & $\begin{array}{l}\text { Environmental Problem } \\
\text { Solving: Flooding; Water } \\
\text { and Soil Loss }\end{array}$ & $\begin{array}{l}\text { Water Flow Regulation, } \\
\text { Natural Hazard Regulation, } \\
\text { Erosion Regulation }\end{array}$ & [63] \\
\hline 2020 & Municipal & $\begin{array}{l}\text { Annual Report on the } \\
\text { Resources and Environment } \\
\text { of Shanghai }\end{array}$ & $\begin{array}{l}\text { Environmental Problem } \\
\text { Solving: Air Pollution; } \\
\text { Water Pollution }\end{array}$ & $\begin{array}{l}\text { Air Quality Regulation; } \\
\text { Water } \\
\text { Purification, Freshwater }\end{array}$ & [50] \\
\hline
\end{tabular}

\subsection{Link Problems and Demands to Relevant Ecosystem Services}

Link problems to RS: urban sprawl caused a massive amount of fragile ecosystem and the important ecological space crowding or damaged $[64,65]$, leading to degradation of ecosystems and reducing supply to the multiple functions of the ecosystem [66], causing spatial mismatches between the supply and demand of multiple ES and resulted in environmental problems, such as flooding [52], water shortage [53], air pollution [15], greenhouse effect [54], etc. Based on the identification of environmental problems and their causal relationship to ES, eight RS targeted to regional and urban environmental problems 
were identified by local experts in the YRDUA (Table 2): global climate regulation, local climate regulation, air quality regulation, water flow regulation, water purification, erosion regulation, natural hazard regulation, and pollination.

Link material demands to PS: in some cases, forces on the demand side of economic growth [67] or population growth [68] are more influential than forces on the supply side. A highly agglomerated population generates acute social and economic activities, applies too much pressure on the ecological environment in the regions, and may also pose certain threats for social stability [69,70]. The population density in the Yangtze River Delta metropolitan region shows an overall characteristic of being higher in the north and lower in the south; that is, Shanghai had the highest population density, and the eight cities in Jiangsu Province have a higher population density than the six cities in Zhejiang Province $[69,70]$. High population density always means high demand for the total amount of different types of multiple ES supply in the YRDUA [12,15,36]. Based on high material demands and consumption generated by huge population numbers and high economic development in the YRDUA, six PS were identified by local experts: crops, biomass for energy, livestock (domestic), timber, aquaculture, and freshwater.

Link spiritual demands to CS: For CS (such as recreation and tourism), the carrying capacity and accessibility of urban green space is an important factor in the matching of supply and demand $[15,35]$. Based on spiritual demands for comprehensive development (Table 2), four CS were identified by local experts: recreation and tourism, landscape aesthetics and inspiration, knowledge systems, and cultural heritage and cultural diversity.

\subsection{Establish Ecosystem Services Supply-Demand Matrix}

In the study, we employed national land use datasets for classification of land use/land cover (LULC) in the YRDUA in 2018, which were produced by the Institute of Remote Sensing and Digital Earth, Chinese Academy of Sciences through interpretation of the Landsat TM or ETM images at a $30 \mathrm{~m}$ resolution. The overall accuracy of classification with ground-based survey data was over $85.35 \%$.

Firstly, we corresponded CORINE land cover system with a local land cover system with local expert knowledge for establishment of ES supply-demand land cover matrix (Table 3). There are sixteen different land cover classes: (1) urban land, (2) country residential land, (3) other built-up land, (4) paddy fields, (5) rainfed croplands, (6) forest land, (7) open forest land, (8) other forest land (orchards), (9) shrub land, (10) grassland, (11) bare land, (12) inland marshes, (13) salt marshes, (14) lakes, (15) ponds, and (16) river and streams.

Secondly, we interviewed twenty local experts for ES assessment, eight from government agencies (two from Shanghai, two from Jiangsu, two from Zhejiang, two from Anhui Province), three from East China Normal University, one from Nanjing University, three from Anhui Normal University, one from Jiangsu University, two from an NGO in Zhejiang Province, and a green enterprise in Jiangsu. All experts are familiar with the YRDUA. 
Table 3. Relationship between CORINE and Yangtze River Delta Urban Agglomeration System.

\begin{tabular}{|c|c|c|}
\hline CORINE Land Cover & YRDUA Land Cover & Ecosystem Types \\
\hline Continuous urban fabric & Urban land & \multirow{3}{*}{ Urban } \\
\hline Discontinuous urban fabric & Country residential land & \\
\hline Construction sites & Other built-up land & \\
\hline Non-irrigated arable land & Rainfed croplands & \multirow{2}{*}{ Cropland } \\
\hline Permanently irrigated arable land & Paddy fields & \\
\hline Broad-leaved forest & \multirow{3}{*}{$\begin{array}{l}\text { Forest land/Open Forest } \\
\text { land/Other woodland }\end{array}$} & \multirow{4}{*}{ Woodland and forest } \\
\hline Coniferous forest & & \\
\hline Mixed forest & & \\
\hline Transitional woodland shrub & Shrub land & \\
\hline Natural grassland & Grassland & Grassland \\
\hline Bare rock & Bareland & Sparsely vegetated areas \\
\hline Inland marshes & Inland marshes & \multirow{2}{*}{ Wetlands } \\
\hline Salt marshes & Salt marshes & \\
\hline Water bodies & Lakes/Ponds & \multirow{2}{*}{ Rivers and lakes } \\
\hline Water courses & River and Streams & \\
\hline
\end{tabular}

Thirdly, we established the ES supply-demand matrix by relating the sixteen land cover classes with the eighteen ES for the YRDUA (Tables 4 and 5). In the first step, we assigned a score for each matrix sheet simply by applying the original matrix presented by Burkhard, Kandziora, Hou, and Müller [10]. Although the original score matrix focused on the European context, it provides a good reference for China. Land cover types in Burkhard's European studies could correspond to China's local land covers types that provided comparable ES supply capacities [36,47,71], though these capacities were modified by local expert's knowledge according to the local socio-ecological background (e.g., vegetation, terrain, hydrology) [6,47,51]. For estimating the ES demands, RS and PS estimation were based on local population density and average consumption patterns but also on land use activities and on their demands for certain services $[6,15,35,51]$. For instance, population density above 20,000 people per kilometers showed a very high demand in multiple RS and PS mainly distributed in the urban land in cities, e.g., Shanghai Municipality and Nanjing in Province (Figure 3). For CS estimation, a multiplication of the population density and the local government guidance on green space provision per capita during the study period were applied for scores modification [12,35]. For example, $60 \mathrm{~m}^{2}$ per person of ecological land (forest lands, wetlands) suggested in local studies were considered by local experts in estimation [72].

Then, we divided twenty experts into four groups according to their locations, with five experts in each group: Shanghai group, Zhejiang group, Jiangsu group, and Anhui Group. We calculated the 'Median' scores of experts in each group as the final score for each ES to each land cover [51]. 
Table 4. Ecosystem services supply matrix. Scale from $0-=$ no relevant flow; $1=$ low relevant flow; $2=$ relevant flow; 3- = medium relevant flow; 4- = high relevant flow; and 5- = very high (maximum) relevant flow (After Burkhard et al., 2014).

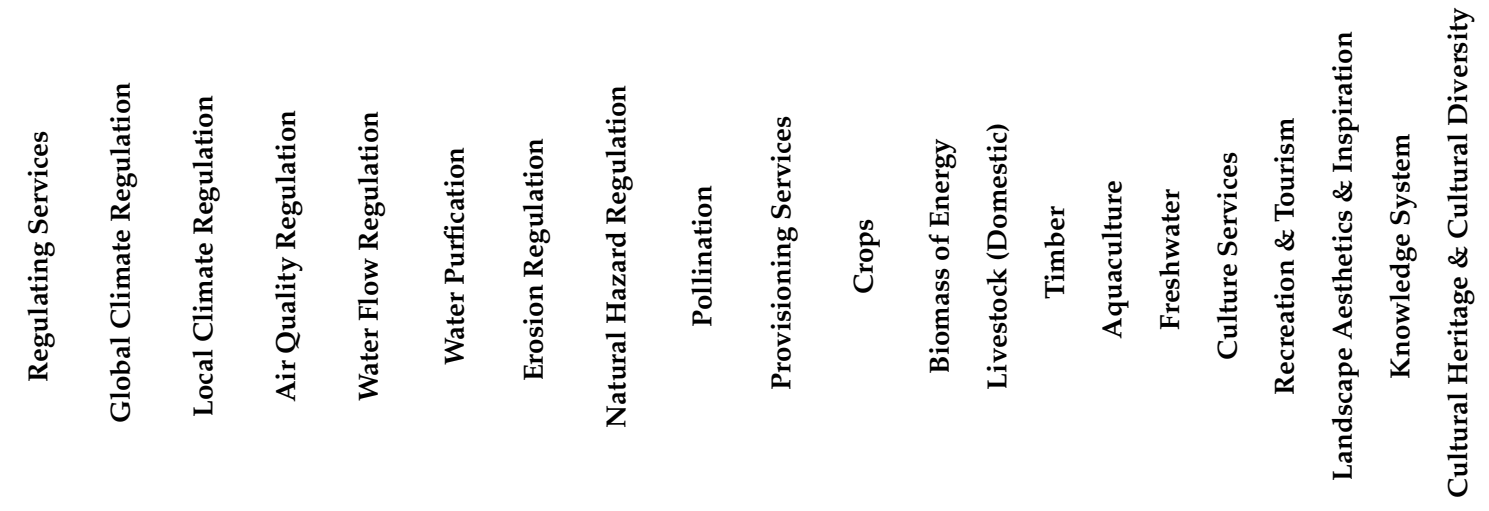

\begin{tabular}{|c|c|c|c|c|c|c|c|c|c|c|c|c|c|c|c|c|c|c|}
\hline Paddy fields & 0 & 2 & 1 & 4 & 0 & 0 & 0 & 1 & 4 & 1 & 0 & 0 & 0 & 0 & 1 & 1 & 1 & 2 \\
\hline Rainfed Cropland & 1 & 2 & 1 & 2 & 0 & 0 & 1 & 3 & 4 & 4 & 0 & 0 & 0 & 0 & 1 & 1 & 1 & $\overline{1}$ \\
\hline Closed forest land & 4 & 5 & 5 & 3 & 4 & 5 & 3 & 1 & 0 & 1 & 0 & 2 & 0 & 0 & 4 & 4 & 4 & 2 \\
\hline Shrub land & 2 & 2 & 1 & 1 & 2 & 1 & 1 & 1 & 0 & 1 & 0 & 1 & 0 & 0 & 2 & 3 & 4 & 1 \\
\hline Open forest land & 2 & 4 & 4 & 2 & 3 & 4 & 2 & 0 & 0 & 1 & 0 & 2 & 0 & 0 & 3 & 3 & 3 & 1 \\
\hline Other woodland & 2 & 2 & 2 & 2 & 1 & 2 & 2 & 3 & 0 & 0 & 0 & 0 & 0 & 0 & 2 & 1 & 1 & 3 \\
\hline Grassland & 2 & 2 & 0 & 1 & 3 & 5 & 1 & 2 & 0 & 0 & 2 & 0 & 0 & 0 & 3 & 4 & 4 & 2 \\
\hline River and Streams & 0 & 1 & 0 & 3 & 3 & 0 & 3 & 0 & 0 & 2 & 0 & 0 & 3 & 3 & 4 & 4 & 3 & 2 \\
\hline Lakes & 1 & 3 & 0 & 3 & 2 & 0 & 3 & 0 & 0 & 0 & 0 & 0 & 3 & 2 & 5 & 4 & 3 & 2 \\
\hline Ponds & 0 & 2 & 0 & 2 & 1 & 0 & 1 & 0 & 0 & 0 & 1 & 0 & 4 & 0 & 1 & 1 & 1 & 1 \\
\hline Salt marshes & 0 & 1 & 0 & 1 & 1 & 2 & 1 & 4 & 0 & 0 & 1 & 0 & 0 & 0 & 3 & 2 & 3 & 0 \\
\hline Inland marshes & 2 & 2 & 0 & 2 & 2 & 1 & 4 & 1 & 0 & 0 & 1 & 0 & 0 & 0 & 1 & 2 & 3 & 1 \\
\hline Urban land & 0 & 0 & 0 & 0 & 0 & 2 & 0 & 1 & 0 & 0 & 0 & 0 & 0 & 0 & 3 & 2 & 2 & 1 \\
\hline Contry residential land & 0 & 0 & 0 & 0 & 0 & 1 & 0 & 2 & 0 & 0 & 0 & 0 & 0 & 0 & 2 & 1 & 2 & 2 \\
\hline Other build-up land & 0 & 0 & 0 & 0 & 0 & 0 & 0 & 0 & 0 & 0 & 0 & 0 & 0 & 0 & 0 & 0 & 0 & 1 \\
\hline Bareland & 0 & 0 & 0 & 0 & 1 & 1 & 0 & 0 & 0 & 0 & 0 & 0 & 0 & 0 & 2 & 3 & 2 & 1 \\
\hline
\end{tabular}

Table 5. Ecosystem services demand matrix. Scale from 0 - = no relevant demand; 1 = low relevant demand; $2=$ relevant demand; 3- = medium relevant demand; 4- = high relevant demand; and 5- = very high (maximum) relevant demand (After Burkhard et al., 2014).

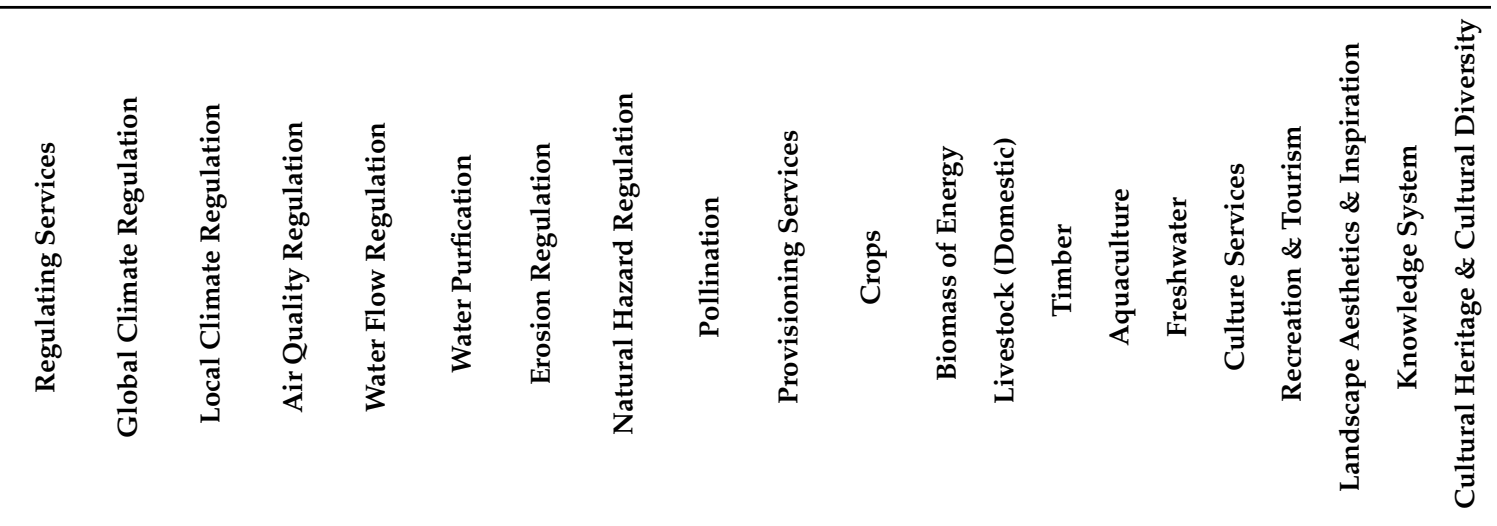

\begin{tabular}{ccccccccccccccccccccc}
\hline Paddy fields & 2 & 2 & 1 & 5 & 5 & 2 & 2 & 2 & & 0 & 1 & 0 & 0 & 0 & 5 & & 0 & 0 & 2 & 3 \\
Rainfed Cropland & 2 & 2 & 1 & 2 & 0 & 3 & 2 & 3 & & 0 & 1 & 0 & 1 & 0 & 0 & & 2 & 1 & 2 & 3 \\
Closed forest land & 0 & 0 & 0 & 0 & 0 & 0 & 0 & 0 & & 0 & 0 & 0 & 0 & 0 & 0 & & 0 & 0 & 0 & 0 \\
Shrub land & 0 & 0 & 0 & 0 & 0 & 0 & 0 & 0 & & 0 & 0 & 0 & 0 & 0 & 0 & 0 & 0 & 0 & 0 \\
Open forest land & 0 & 0 & 0 & 0 & 0 & 0 & 0 & 0 & & 0 & 0 & 0 & 0 & 0 & 0 & 0 & 0 & 0 & 0 \\
Other woodland & 1 & 2 & 1 & 2 & 3 & 1 & 3 & 3 & & 0 & 1 & 0 & 1 & 0 & 0 & 2 & 1 & 2 & 3 \\
Grassland & 0 & 0 & 0 & 0 & 0 & 0 & 0 & 0 & & 0 & 0 & 0 & 0 & 0 & 0 & 0 & 0 & 0 & 0 \\
River and Streams & 0 & 0 & 0 & 0 & 0 & 0 & 0 & 0 & & 0 & 0 & 0 & 0 & 0 & 0 & 0 & 0 & 0 & 0 \\
Lakes & 0 & 0 & 0 & 0 & 0 & 0 & 0 & 0 & & 0 & 0 & 0 & 0 & 0 & 0 & 0 & 0 & 0 & 0 \\
Ponds & 0 & 0 & 0 & 0 & 0 & 0 & 0 & 0 & & 0 & 0 & 0 & 0 & 0 & 0 & 0 & 0 & 0 & 0 \\
Salt marshes & 0 & 0 & 0 & 0 & 0 & 0 & 0 & 0 & & 0 & 0 & 0 & 0 & 0 & 0 & 0 & 0 & 0 & 0 \\
Inland marshes & 0 & 0 & 0 & 0 & 0 & 0 & 0 & 0 & & 0 & 0 & 0 & 0 & 0 & 0 & 0 & 0 & 0 & 0 \\
Urban land & 4 & 5 & 5 & 4 & 5 & 1 & 5 & 1 & & 5 & 5 & 5 & 3 & 5 & 5 & 4 & 4 & 3 & 4 \\
Contry residential land & 3 & 5 & 5 & 5 & 4 & 1 & 4 & 2 & & 4 & 4 & 4 & 3 & 4 & 5 & 4 & 4 & 3 & 2 \\
Other build-up land & 1 & 2 & 1 & 2 & 2 & 2 & 3 & 0 & & 0 & 4 & 0 & 4 & 0 & 2 & 0 & 0 & 0 & 0 \\
Bareland & 0 & 0 & 0 & 0 & 0 & 0 & 0 & 0 & & 0 & 0 & 0 & 0 & 0 & 0 & 0 & 0 & 0 & 0 \\
\hline
\end{tabular}




\subsection{Assess ES Supply-Demand Amount and Type (Mis)Matches}

Based on the double-indices method put forward in 2.4, ES supply-demand amount and type (mis)matches of twenty-six cities in the YRDUA were assessed. The results are as follows: (Figures 4 and 5)
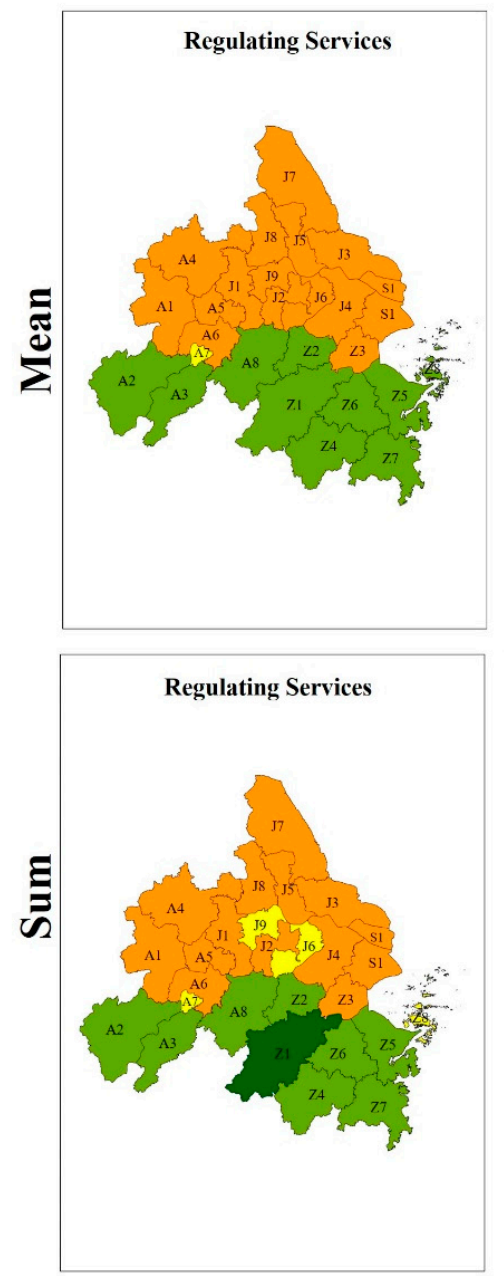
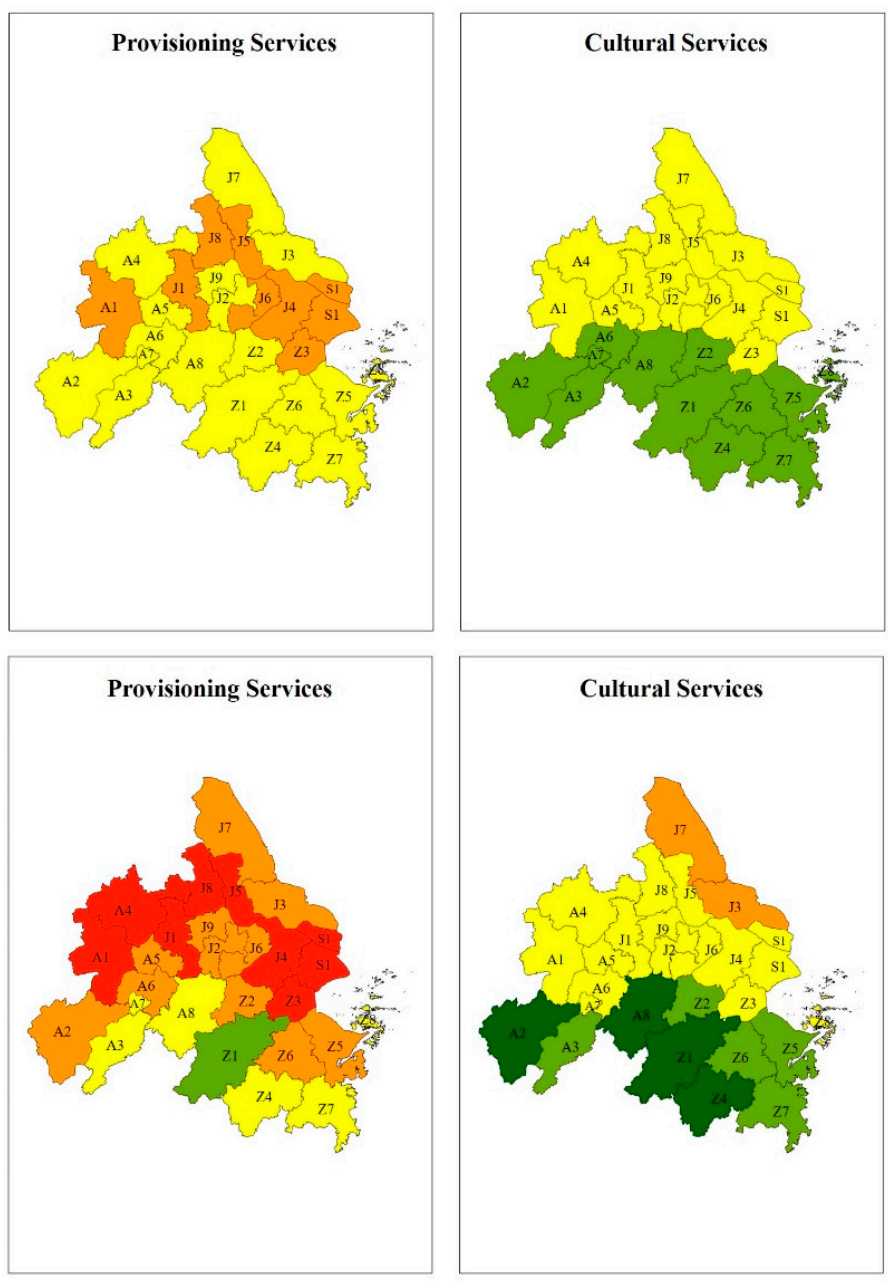

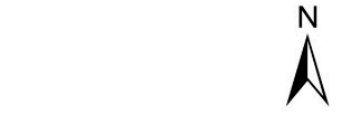

$100200 \quad 400$ Kilometers

\section{Level}

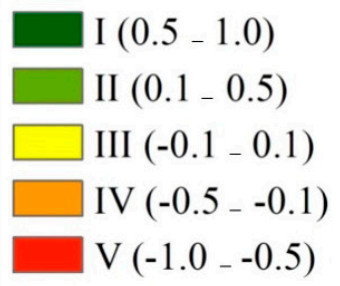

Figure 4. Spatial Pattern and Levels of Mean and Sum of Regulating Services, Provisioning Services and Cultural Services: (A1) Hefei, (A2) Anqing, (A3) Chizhou, (A4) Chuzhou, (A5) Ma'anshan, (A6) Tongling, (A7) Wuhu, (A8) Xuancheng in Anhui Province; (J1) Nanjing, (J2) Changzhou, (J3) Nantong, (J4) Suzhou, (J5) Taizhou-J, (J6) Wuxi, (J7)Yancheng, (J8) Yangzhou, (J9) Zhenjiang in Jiangsu Province; (S1) Shanghai Municipality; (Z1) Hangzhou, (Z2) Huzhou, (Z3) Jiaxing, (Z4) Jinhua, (Z5) Ningbo, (Z6) Shaoxing, (Z7) Taizhou-Z, and (Z8) Zhoushan. 

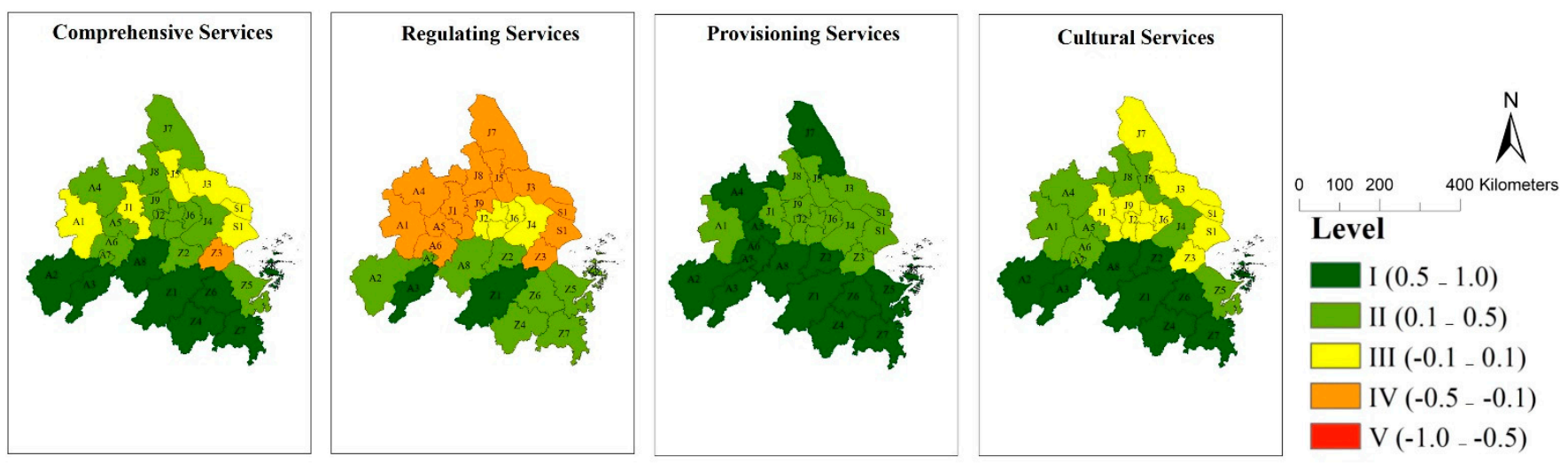

Figure 5. Spatial Pattern and Levels of Type of Comprehensive Services, Regulating Services, Provisioning Services and Cultural Services: (A1) Hefei, (A2) Anqing, (A3) Chizhou, (A4) Chuzhou, (A5) Ma'anshan, (A6) Tongling, (A7) Wuhu, (A8) Xuancheng in Anhui Province; (J1) Nanjing, (J2) Changzhou, (J3) Nantong, (J4) Suzhou, (J5) Taizhou-J, (J6) Wuxi, (J7)Yancheng, (J8) Yangzhou, (J9) Zhenjiang in Jiangsu Province; (S1) Shanghai Municipality; (Z1) Hangzhou, (Z2) Huzhou, (Z3) Jiaxing, (Z4) Jinhua, (Z5) Ningbo, (Z6) Shaoxing, (Z7) Taizhou-Z, and (Z8) Zhoushan.

\subsubsection{Assess City ES Supply-Demand (Mis)Matches Based on the ES Amount Index}

The results of the mean index assessment were: (1) ten surplus cities which were medium surplus (e.g., A2, Z1, Z2, Z4, etc.), one balance city (A7), and fifteen deficit cities which were medium deficit (e.g., A1, J1, S1, Z3, etc.) in RS; (2) no surplus cities and eighteen match cities (e.g., A2, J2, Z1, Z4, etc.) and eight deficit cities (e.g., A1, J1, S1, Z3, etc.) in PS; (3) twelve surplus cities which were medium surplus (e.g., A2, Z1, Z2, Z4, etc.), fourteen match cities (e.g., A1, J1, S1, Z3, etc.) in CS.

The results of the sum index assessment were: (1) one high surplus city (Z1), and eight medium surplus cities (e.g., A2, Z2, Z4, Z5, etc.), four match cities (A7, J6, J9, Z8), and thirteen medium deficit cities (e.g., A1, J1, S1, Z3, etc.) in RS; (2) one surplus city (Z1), six match cities (e.g., A3, Z4, Z7, etc.), eleven medium deficit cities (e.g., A2, J2, J6, Z5, etc.), and eight high deficit cities (e.g., A1, J1, S1, Z3, etc.) in PS; (3) four high surplus cities (A2, $A 8, Z 1, Z 4)$, five medium surplus cities (A3, Z2, Z5-Z7), fifteen match cities (e.g., A1, J1, S1, $\mathrm{Z3}$, etc.), and two medium deficit cites (J3, J7) in CS.

We defined fourteen cities (S1, J1-J9, A1, A4-A5, Z3) as southern cities and twelve cities (Z1-Z2, Z4-Z8, A2-A3, A6-A8) as northern cities of the region according to their locations. In general, twenty-six cities displayed a similar spatial pattern in mean and sum (mis)match index in RS, PS, and CS (Figure 4). However, the match levels of southern cities were mainly higher than northern cities in RS, PS, and CS.

\subsubsection{Assess City ES Supply-Demand (Mis)Matches Based on the Type Index}

The results of type index assessment were: (1) eight high match cities (e.g., A3, Z1, Z4, Z6, etc.), twelve medium match cities (e.g., A4, A7, J4, Z2, etc.), five match cities (A1, J1, J3, $\mathrm{J} 5, \mathrm{~S} 1$ ) and one medium mismatch city (Z3) in the Comprehensive Services; (2) two high match cities (A3, Z1), nine medium match cities (e.g., A7, Z2, Z4, Z6, etc.), three match cities (J2, J4, J6), and twelve medium mismatch cities (e.g., A1, J1, S1, Z3, etc.) in RS; (3) fifteen high match cities (e.g., A3, J7, Z1, Z6.) and eleven medium match cities (e.g., A1, J1, S1, Z3, etc.) in PS; (4) nine high match cities (e.g., A2, Z1, Z2, Z4, etc.), nine medium match cities(e.g., A4, A7, J4, J5, etc.), and eight match cities (e.g., J1, J6, S1, Z3, etc.) in CS.

In general, twenty-six cities displayed a similar spatial pattern in type (mis)matches index in the Comprehensive Services and CS (Figure 5). However, northern cities were Level IV and Level III, whereas southern cities were mainly Level II. 


\subsection{Classify Cities by Double-Indices Assessment}

The results integrating ES amount and type (mis)matches assessment in twenty-six cities are as follows:

Mean-Type (Figure 6): (1) for RS, twenty-six cities can be classified into five kinds of (mis)match cities: two cities (A3 and Z1) were 'medium match, high match', eight cities (e.g., A2, Z2, Z4 and Z6) were 'medium match, medium match', one city (A7) was 'match, medium match', three cities (J2, J4, J6) were 'medium mismatch, match' and twelve cities (e.g., A1, J1, S1 and Z3) were 'medium mismatch, medium mismatch'; (2) for PS, three kinds of (mis)match cities: fifteen cities (e.g., A2, A3, Z1, and Z2) were 'match, high match', three cities (J2, J3, J9) were 'match, medium match', and eight cities (e.g., A1, J1, S1, and Z3) were 'medium mismatch (IV), medium match'; (3) For CS, four kinds of (mis)match cities: nine cities (e.g., A2, Z1, Z2, and Z4) were 'medium match, high match', three cities (A6, A7, Z5) were 'medium match (II), medium match', six cities (A1, A4, J4, J5) were 'match, medium match', and eight cities (e.g., J1, J2, S1, and Z3) were 'match, match'.

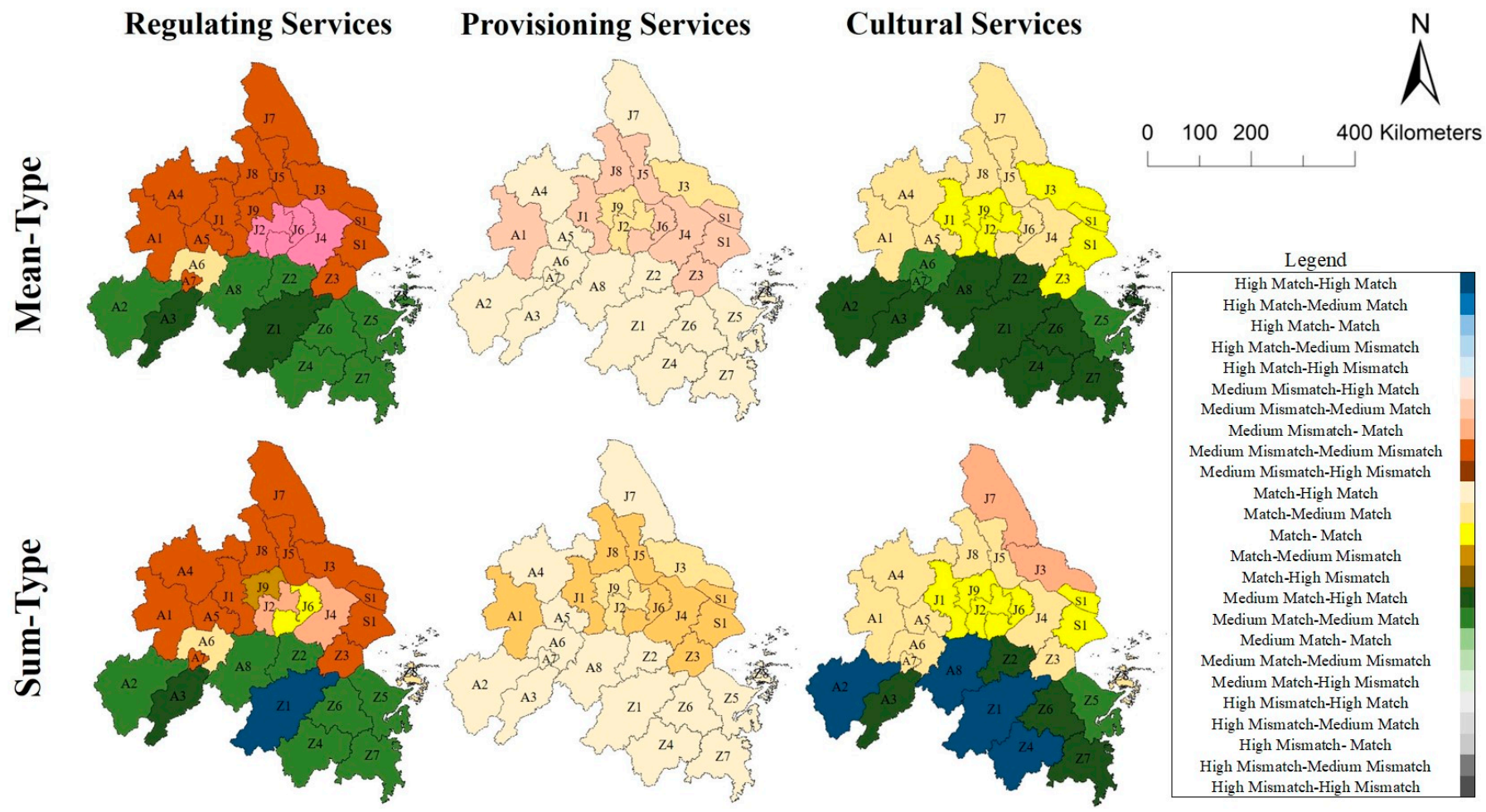

Figure 6. Double-indices (Mean-Type and Sum-Type) Spatial Pattern of Regulating Services, Provisioning Services, and Cultural Services: (A1) Hefei, (A2) Anqing, (A3) Chizhou, (A4) Chuzhou, (A5) Ma'anshan, (A6) Tongling, (A7) Wuhu, (A8) Xuancheng in Anhui Province; (J1) Nanjing, (J2) Changzhou, (J3) Nantong, (J4) Suzhou, (J5) Taizhou-J, (J6) Wuxi, (J7)Yancheng, (J8) Yangzhou, (J9) Zhenjiang in Jiangsu Province; (S1) Shanghai Municipality; (Z1) Hangzhou, (Z2) Huzhou, (Z3) Jiaxing, (Z4) Jinhua, (Z5) Ningbo, (Z6) Shaoxing, (Z7) Taizhou-Z, and (Z8) Zhoushan.

Sum-Type (Figure 6): (1) for RS, twenty-six cities can be classified into eight kinds of (mis)match cities: one city (Z1) was 'high match, high match', one city (A3) was 'medium match, high match', seven cities (e.g., A2, Z2, Z4 and Z6) were 'medium match, medium match', two cities (A7, Z8) were 'balance or match, medium match', one city (J6) was 'match, match', two cities (J2, J4) were 'medium mismatch, match', one city (J9) was 'match, medium balance', eleven cities (e.g., A1, J1, S1, and Z3) were 'medium mismatch, medium mismatch'; (2) for PS, three kinds of (mis)match cities: fifteen cities (e.g., A2, A3, Z1 and Z2) were 'match, high match', three cities (J2, J3, J9) were 'match, medium match', and eight cities (e.g., A1, J1, S1 and Z3) were 'medium mismatch, medium match'; (3) for CS, six kinds of (mis)match cities: four cities (A2, A8, Z1, Z4) were 'high match, high match', four cities (A3, Z2, Z6, Z7) were 'medium match, high match', one city (Z5) was 'medium 
match, medium match', nine cities (e.g., A1, A4, J4, and J5) were 'match, medium match', six cities (e.g.,J1, J2, S1 and Z3) were 'match, match' and two cities (J3, J7) were 'medium mismatch, match'.

\subsection{Design Differential Land Use Management Strategies}

Based on the results of the double-indices assessment, four kinds of strategies were designed for cities in the YRDUA:

(1) For the cities matched in both amount and type (Figure 6) - 'medium match, high match', 'medium match, medium match', and 'match, medium match' in RS, 'match, high match' in PS, and 'medium match, high match' in CS-ecosystem conservation policies, e.g., Ecological Redline Policy, should be the main measurement of these cities for RS, PS, and CS management. These cities can be potential multiple ES providing areas for cities with mismatches in both amount and type. For example, forest, wetland, and other natural ecosystem conservation should be strengthened in the transboundary areas of cities, and the implementation of joint construction and co-protection of land use management should be carried out.

(2) For the cities matched in amount but mismatched in type (Figure 6) -'match, medium mismatch' in RS, 'match, medium mismatch' in PS, and 'match, medium mismatch' and 'match, mismatch' in CS, i.e., these cities with total balance in ES but mismatches in multiple types of ES-it is suggested to carry out policies that can promote the synergy of multiple ES simultaneously. For example, these cities should carry out the PS supply capacity of cropland ecosystem by 'Prime Farmland Policy', as well as the 'Grain for Green' policy [38] for increasing the RS supply simultaneously, based on studies of ES multifunction management;

(3) For the cities mismatched in both amount and type (Figure 6) - 'medium mismatch, medium mismatch' in RS-it is suggested that urban sprawl and population control policy should be emphasized, especially for PS management, since reducing demands of ES may be more effective if multiple ES supply may be hard to meet the demand. External environmental cooperation among different-level cities should also be carried out, e.g., payment for ES in RS and PS management, and tourism cooperation in CS management, since the demand of multiple ES of these types of cities cannot be satisfied by ES supply itself;

(4) Cities mismatched in amount but matched in type (Figure 6) - 'medium mismatch, match' in RS, 'medium mismatch, medium match' in PS, i.e., cities with a total imbalance in ES but matches in multiple types of ES-should focus on demand control strategies for specific ES.

Differential land use management for cities should be fundamental to the consideration of influences of different natural and anthropogenic factors in cities of an urban agglomeration. In the case study, the spatial mismatches between ES supply and demand in the cities of YRDUA were influenced by both natural and anthropogenic factors $[36,37,47,73,74]$.

On the one hand, there was spatial heterogeneity in the distribution of ecosystems in the YRDUA. The forest ecosystems were the main sources of multiple ES supply, which were mainly distributed in the mountainous areas of southern and western cities with low disturbance of human activities, such as Hangzhou, Anqing. In contrast, the cropland and urban land were the main sources of multiple ES demand, which were mainly distributed in the plain areas of northern and eastern cities with high intensity of human disturbance, such as Shanghai, Suzhou. This was the natural reason that ES supply-demand (mis)matches results showed high spatial autocorrelation that both matches in amount and type in the south and both in mismatches in the north.

On the other hand, concentrated distribution and a huge number of the urban and rural population in the northern and central cities, as well as the economic development, have generated high demand in both total amounts and each type of ES in the YRDUA [37,74]. High-intensity agriculture and urbanization in the north and the middle cities of YRDUA 
destroyed the integrity of regional and urban ecosystems [47], thus weaken ES supply and aggregated the mismatches of ES supply and demand in both total amount and each type of ES in those cities. Moreover, environmental pollution, e.g., air and water environmental pollutions, is also caused by the ES supply-demand mismatch in the north and the middle of the region. For example, the problem of water pollution in the Taihu Lake Basin brought water quality shortage to several cities in the YRDUA [75,76], resulting in mismatches in freshwater provision service and water purification service.

Under the co-effect of natural and anthropogenic factors, a variety of ES supply and demand (mis)match combinations are generated. The objectives of different city management are to manage the co-effect of natural and anthropogenic factors for different (mis)matches combination in different cities. A city that matched in both amount and type assessment, e.g., Hangzhou, should take action in forest ecosystem conservation since the distribution of forest was the main natural factor in ES supply-demand matches of this city. A city that is mismatched in both amount and type assessment, e.g., Shanghai, should control the urban growth and population number to restrict the demand since few natural ecosystems were distributed in the city, and high demand was generated by high population numbers. A city that matched in amount but mismatched in type means the number of ES matches types was fewer than the number of ES mismatches types. For specific ES types matches management, specific natural and anthropogenic factors should be found for specific land use management. A city that mismatched in amount and matched in types means that the overall amount of ES supply cannot match the total demand. Ecosystem conservation policy and population control should be performed simultaneously to make a positive co-effect of natural and anthropogenic factors.

\section{Discussion}

\subsection{ES Framework}

In previous studies, several ES frameworks were put forward for environmental management and decision support $[10,11,47,51,77]$. These ES frameworks have evolved with increasing requirements of environmental management. Earlier frameworks only focused on ES supply-side assessment but ignored the ES demand-side assessment; thus it can only be applied in regional ecosystem conservation management (e.g., ecological redline delineation) $[47,78]$. Then, some frameworks considered both ES supply and demand but did not link ES to LULC types that could not be applied in spatial planning and management [54,79]. Current frameworks considered not only both ES supply and demand but also the link to LULC. Recently, Cai et al. (2020) developed a general ES framework integrating Burkhard's ES supply-demand budget with flow direction analysis, identifying ES city type and spatial relations. This framework could be applied in intercity environmental cooperation and payment for ES mechanisms in a highly urbanized region [51]. Based on previous studies, this study presented a general ES framework for differential city management in an urban agglomeration. This framework was designed for ES supply-demand (mis)match assessment of cities and classified cities based on the assessment for differential land use management in an urban agglomeration.

\subsection{Double-Indices Assessment}

The ES supply-demand amount (mis)match assessment was considered as an important criterion in environmental management at different scales [20,31]. For example, Li et al. (2016) developed an ES supply-demand amount index and addressed the idea of arithmetic mean of balance matches for comprehensive ecological function zone assessment. Lorilla, et al. [80] assessed the ES supply-demand balance matches for islands' sustainable development. Chen et al. (2019) presented and employed the arithmetic mean of the ES supply-demand amount index in a case study of urban land use management in Shanghai Municipality. It is disappointing that these studies do not include the ES supply-demand type (mis)match assessment and ignores some useful information on different types of ES supply and demand for environmental management. This may lead to a biased or 
incomplete decision in environmental management. This study addressed the necessity of including both ES supply-demand type (mis)match assessment and the amount (mis)match assessment for comprehensive environmental management in an urban agglomeration. The double-indices assessment can provide more information for cities' decision-makers for differential governance, such as different levels and spatial patterns of (mis)matches. In the case study, we found differences in cities with inconsistent matches levels in the double-indices assessment within the single-index assessment. For instance, compared with the single-index assessment, A7 of 'match, medium match' and (J2, J4, J6) of 'medium mismatch, match' were new groups for RS in the Mean-Type double-indices assessment. For another, (J2, J3, J9) of 'match, medium match' was a new city category for PS in the Sum-Type double-indices assessment compared with the single-index assessment.

\subsection{Contributions and Limitations}

In this study, we developed a general framework based on ES supply-demand (mis)match assessment for differential city management in an urban agglomeration. This framework not only made up for deficiencies in unified city management in socio-ecological integration of an urban agglomeration but also provide a new insight for environmental management at other scales. The aim of the double-indices assessment was to assess ES supply-demand (mis)matches in amount and type. Prior to the single-index assessment, the double-indices assessment can help to understand the ES supply-demand status comprehensively in the study area.

This study has limitations, as follows: The scoring of ES supply-demand by local expert knowledge has certain uncertainty [36,81], especially for scoring ES demands, and it was influenced by several factors, including data availability, population density, local income, age, etc. Therefore, the results of the study should be carefully applied in other areas and should be calibrated by local data.

\section{Conclusions}

In this study, we combined ES supply-demand amount (mis)match with type (mis)match to present a double-indices assessment method to have a deeper understanding of the ES supply-demand status comprehensively in a study area. A general ES framework with six core steps for differential city management in an urban agglomeration was presented and applied in the ES supply-demand (mis)match assessment of cities in the YRDUA. Twenty-six cities in the YRDUA were classified into five kinds of cities with different levels of ES supply-demand (mis)matches for RS, three kinds of cities for PS, and four kinds of cities for CS. Differential city management strategies were designed. Despite its limitations, this study can be a reference to provide insights into ES supply-demand (mis)match assessment and management.

Author Contributions: Conceptualization, W.C. and Y.C.; methodology, W.C. and Y.C.; formal analysis, W.C. and Y.C.; investigation, H.D. and R.C.; writing-original draft preparation, W.C. and Y.C.; writing—review and editing, W.J., H.D. and R.C.; supervision, W.J., H.D. and R.C.; project administration, Y.C.; funding acquisition, Y.C. All authors have read and agreed to the published version of the manuscript.

Funding: This research was funded by Big Data-Driven Ecological Security and Natural Resources Early Warning Plan, Key Projects of Philosophy and Social Science Research, Chinese Ministry of Education (Grant No. 19JZD023),National Natural Science Foundation of China (Grant No. 31670474) and the National Key Research Program of China (Grant No.2016YFC0502701).

Institutional Review Board Statement: Not applicable.

Informed Consent Statement: Consent was obtained from all participants involved in the study.

Data Availability Statement: Data are contained within the article.

Acknowledgments: The authors gratefully acknowledge the project supported by Big Data-Driven Ecological Security and Natural Resources Early Warning Plan, Key Projects of Philosophy and Social 
Science Research, Chinese Ministry of Education (Grant No. 19JZD023), National Natural Science Foundation of China (Grant No. 31670474), and the National Key Research Program of China (Grant No.2016YFC0502701).

Conflicts of Interest: The authors declare no conflict of interest.

\section{References}

1. Han, J.; Meng, X.; Zhou, X.; Yi, B.; Liu, M.; Xiang, W.-N. A long-term analysis of urbanization process, landscape change, and carbon sources and sinks: A case study in China's Yangtze River Delta region. J. Clean. Prod. 2017, 141, 1040-1050. [CrossRef]

2. Yanez Soria, K.; Ribeiro Palacios, M.; Morales Gomez, C.A. Governance and policy limitations for sustainable urban land planning. The case of Mexico. J. Environ. Manag. 2020, 259, 109575. [CrossRef]

3. Oliveira, G.; Vidal, D.; Ferraz, M. Urban Lifestyles and Consumption Patterns; Springer: Berlin, Germany, 2020; pp. 851-860.

4. Haas, J.; Ban, Y. Urban growth and environmental impacts in Jing-Jin-Ji, the Yangtze, River Delta and the Pearl River Delta. Int. J. Appl. Earth Obs. Geoinf. 2014, 30, 42-55. [CrossRef]

5. Vidal, D.G.; Fernandes, C.O.; Viterbo, L.M.F.; Vilaca, H.; Barros, N.; Maia, R.L. Combining an evaluation grid application to assess ecosystem services of urban green spaces and a socioeconomic spatial analysis. Int. J. Sustain. Dev. World Ecol. 2021, 28, 291-302. [CrossRef]

6. Cai, W.; Jiang, W.; Cai, Y. Developing an Ecosystem Services-Based Approach for Land Use Planning. Land 2021, $10,419$. [CrossRef]

7. Kusi, K.K.; Khattabi, A.; Mhammdi, N.; Lahssini, S. Prospective evaluation of the impact of land use change on ecosystem services in the Ourika watershed, Morocco. Land Use Policy 2020, 97, 104796. [CrossRef]

8. Hasan, S.S.; Zhen, L.; Miah, M.G.; Ahamed, T.; Samie, A. Impact of land use change on ecosystem services: A review. Environ. Dev. 2020, 34, 100527. [CrossRef]

9. Potschin, M.B.; Haines-Young, R.H. Ecosystem services: Exploring a geographical perspective. Prog. Phys. Geogr. 2011, 35, 575-594. [CrossRef]

10. Burkhard, B.; Kandziora, M.; Hou, Y.; Müller, F. Ecosystem Service Potentials, Flows and Demands-Concepts for Spatial Localisation, Indication and Quantification. Landsc. Online 2014, 34, 1-32. [CrossRef]

11. Burkhard, B.; Kroll, F.; Nedkov, S.; Müller, F. Mapping ecosystem service supply, demand and budgets. Ecol. Indic. 2012, 21, 17-29. [CrossRef]

12. Wei, H.; Fan, W.; Wang, X.; Lu, N.; Dong, X.; Zhao, Y.; Ya, X.; Zhao, Y. Integrating supply and social demand in ecosystem services assessment: A review. Ecosyst. Serv. 2017, 25, 15-27. [CrossRef]

13. Geijzendorffer, I.R.; Martín-López, B.; Roche, P.K. Improving the identification of mismatches in ecosystem services assessments. Ecol. Indic. 2015, 52, 320-331. [CrossRef]

14. Mashizi, A.K.; Sharafatmandrad, M. Investigating tradeoffs between supply, use and demand of ecosystem services and their effective drivers for sustainable environmental management. J. Environ. Manag. 2021, 289, 112534. [CrossRef] [PubMed]

15. Chen, J.; Jiang, B.; Bai, Y.; Xu, X.; Alatalo, J.M. Quantifying ecosystem services supply and demand shortfalls and mismatches for management optimisation. Sci. Total Environ. 2019, 650, 1426-1439. [CrossRef]

16. Ouyang, Z.; Zheng, H.; Xiao, Y.; Polasky, S.; Liu, J.; Xu, W.; Wang, Q.; Zhang, L.; Xiao, Y.; Rao, E.; et al. Improvements in ecosystem services from investments in natural capital. Science 2016, 352, 1455-1459. [CrossRef]

17. Jiang, W. Ecosystem services research in China: A critical review. Ecosyst. Serv. 2017, 26, 10-16. [CrossRef]

18. Turner, K.G.; Anderson, S.; Gonzales-Chang, M.; Costanza, R.; Courville, S.; Dalgaard, T.; Dominati, E.; Kubiszewski, I.; Ogilvy, S.; Porfirio, L.; et al. A review of methods, data, and models to assess changes in the value of ecosystem services from land degradation and restoration. Ecol. Model. 2016, 319, 190-207. [CrossRef]

19. Ndong, G.O.; Therond, O.; Cousin, I. Analysis of relationships between ecosystem services: A generic classification and review of the literature. Ecosyst. Serv. 2020, 43, 101120. [CrossRef]

20. Campagne, C.S.; Roche, P.; Müller, F.; Burkhard, B. Ten years of ecosystem services matrix: Review of a (r)evolution. One Ecosyst. 2020, 5, e51103. [CrossRef]

21. Mehring, M.; Ott, E.; Hummel, D. Ecosystem services supply and demand assessment: Why social-ecological dynamics matter. Ecosyst. Serv. 2018, 30, 124-125. [CrossRef]

22. Schirpke, U.; Candiago, S.; Vigl, L.E.; Jager, H.; Labadini, A.; Marsoner, T.; Meisch, C.; Tasser, E.; Tappeiner, U. Integrating supply, flow and demand to enhance the understanding of interactions among multiple ecosystem services. Sci. Total Environ. 2019, 651, 928-941. [CrossRef] [PubMed]

23. Uthes, S.; Matzdorf, B. Budgeting for government-financed PES: Does ecosystem service demand equal ecosystem service supply? Ecosyst. Serv. 2016, 17, 255-264. [CrossRef]

24. Vrebos, D.; Staes, J.; Vandenbroucke, T.; D’Haeyer, T.; Johnston, R.; Muhumuza, M.; Kasabeke, C.; Meire, P. Mapping ecosystem service flows with land cover scoring maps for data-scarce regions. Ecosyst. Serv. 2015, 13, 28-40. [CrossRef]

25. Feurer, M.; Zaehringer, J.G.; Heinimann, A.; Naing, S.M.; Blaser, J.; Celio, E. Quantifying local ecosystem service outcomes by modelling their supply, demand and flow in Myanmar's forest frontier landscape. J. Land Use Sci. 2021, 16, 55-93. [CrossRef]

26. Martinez-Lopez, J.; Bagstad, K.J.; Balbi, S.; Magrach, A.; Voigt, B.; Athanasiadis, L.; Pascual, M.; Willcock, S.; Villa, F. Towards globally customizable ecosystem service models. Sci. Total Environ. 2019, 650, 2325-2336. [CrossRef] 
27. Shen, J.; Du, S.; Huang, Q.; Yin, J.; Zhang, M.; Wen, J.; Gao, J. Mapping the city-scale supply and demand of ecosystem flood regulation services-A case study in Shanghai. Ecol. Indic. 2019, 106, 105544. [CrossRef]

28. Li, F.; Guo, S.; Li, D.; Li, X.; Li, J.; Xie, S. A multi-criteria spatial approach for mapping urban ecosystem services demand. Ecol. Indic. 2020, 112, 106119. [CrossRef]

29. Paudyal, K.; Baral, H.; Burkhard, B.; Bhandari, S.P.; Keenan, R.J. Participatory assessment and mapping of ecosystem services in a data-poor region: Case study of community-managed forests in central Nepal. Ecosyst. Serv. 2015, 13, 81-92. [CrossRef]

30. Peña, L.; Casado-Arzuaga, I.; Onaindia, M. Mapping recreation supply and demand using an ecological and a social evaluation approach. Ecosyst. Serv. 2015, 13, 108-118. [CrossRef]

31. Li, J.; Jiang, H.; Bai, Y.; Alatalo, J.M.; Li, X.; Jiang, H.; Liu, G.; Xu, J. Indicators for spatial-temporal comparisons of ecosystem service status between regions: A case study of the Taihu River Basin, China. Ecol. Indic. 2016, 60, 1008-1016. [CrossRef]

32. Bryan, B.A.; Ye, Y.; Zhang, J.; Connor, J.D. Land-use change impacts on ecosystem services value: Incorporating the scarcity effects of supply and demand dynamics. Ecosyst. Serv. 2018, 32, 144-157. [CrossRef]

33. Goldenberg, R.; Kalantari, Z.; Cvetkovic, V.; Mortberg, U.; Deal, B.; Destouni, G. Distinction, quantification and mapping of potential and realized supply-demand of flow-dependent ecosystem services. Sci. Total Environ. 2017, 593, 599-609. [CrossRef] [PubMed]

34. Baro, F; Haase, D.; Gomez-Baggethun, E.; Frantzeskaki, N. Mismatches between ecosystem services supply and demand in urban areas: A quantitative assessment in five European cities. Ecol. Indic. 2015, 55, 146-158. [CrossRef]

35. Jiang, B.; Bai, Y.; Chen, J.; Alatalo, J.M.; Xu, X.; Liu, G.; Wang, Q. Land management to reconcile ecosystem services supply and demand mismatches-A case study in Shanghai municipality, China. Land Degrad. Dev. 2020, 31, 2684-2699. [CrossRef]

36. Tao, Y.; Wang, H.; Ou, W.; Guo, J. A land-cover-based approach to assessing ecosystem services supply and demand dynamics in the rapidly urbanizing Yangtze River Delta region. Land Use Policy 2018, 72, 250-258. [CrossRef]

37. Sun, W.; Li, D.; Wang, X.; Li, R.; Li, K.; Xie, Y. Exploring the scale effects, trade-offs and driving forces of the mismatch of ecosystem services. Ecol. Indic. 2019, 103, 617-629. [CrossRef]

38. Qiao, X.; Gu, Y.; Zou, C.; Xu, D.; Wang, L.; Ye, X.; Yang, Y.; Huang, X. Temporal variation and spatial scale dependency of the trade-offs and synergies among multiple ecosystem services in the Taihu Lake Basin of China. Sci. Total Environ. 2019, 651, 218-229. [CrossRef] [PubMed]

39. Maragno, D.; Gaglio, M.; Robbi, M.; Appiotti, F.; Fano, E.A.; Gissi, E. Fine-scale analysis of urban flooding reduction from green infrastructure: An ecosystem services approach for the management of water flows. Ecol. Model. 2018, 386, 1-10. [CrossRef]

40. Fugiel, A.; Burchart-Korol, D.; Czaplicka-Kolarz, K.; Smolinski, A. Environmental impact and damage categories caused by air pollution emissions from mining and quarrying sectors of European countries. J. Clean. Prod. 2017, 143, 159-168. [CrossRef]

41. Haines-Young, R.; Potschin-Young, M. Revision of the Common International Classification for Ecosystem Services (CICES V5.1): A Policy Brief. One Ecosyst. 2018, 3, e27108. [CrossRef]

42. Almeida, C.M.V.B.; Mariano, M.V.; Agostinho, F.; Liu, G.Y.; Yang, Z.F.; Coscieme, L.; Giannetti, B.F. Comparing costs and supply of supporting and regulating services provided by urban parks at different spatial scales. Ecosyst. Serv. 2018, 30, 236-247. [CrossRef]

43. Li, R.; Zheng, H.; Polasky, S.; Hawthorne, P.L.; O'Connor, P.; Wang, L.; Li, R.; Xiao, Y.; Wu, T.; Ouyang, Z. Ecosystem restoration on Hainan Island: Can we optimize for enhancing regulating services and poverty alleviation? Environ. Res. Lett. 2020, 15, 084039. [CrossRef]

44. Kamiyama, C.; Hashimoto, S.; Kohsaka, R.; Saito, O. Non-market food provisioning services via homegardens and communal sharing in satoyama socio-ecological production landscapes on Japan's Noto peninsula. Ecosyst. Serv. 2016, 17, 185-196. [CrossRef]

45. Herrero-Jauregui, C.; Arnaiz-Schmitz, C.; Herrera, L.; Smart, S.M.; Montes, C.; Pineda, F.D.; Fe Schmitz, M. Aligning landscape structure with ecosystem services along an urban-rural gradient. Trade-offs and transitions towards cultural services. Landsc. Ecol. 2019, 34, 1525-1545. [CrossRef]

46. Jarvis, D.; Stoeckl, N.; Liu, H.B. New methods for valuing, and for identifying spatial variations, in cultural services: A case study of the Great Barrier Reef. Ecosyst. Serv. 2017, 24, 58-67. [CrossRef]

47. Cai, W.; Gibbs, D.; Zhang, L.; Ferrier, G.; Cai, Y. Identifying hotspots and management of critical ecosystem services in rapidly urbanizing Yangtze River Delta Region, China. J. Environ. Manag. 2017, 191, 258-267. [CrossRef]

48. Kroll, F.; Mueller, F.; Haase, D.; Fohrer, N. Rural-urban gradient analysis of ecosystem services supply and demand dynamics. Land Use Policy 2012, 29, 521-535. [CrossRef]

49. Lin, M.; Lin, T.; Sun, C.; Jones, L.; Sui, J.; Zhao, Y.; Liu, J.; Xing, L.; Ye, H.; Zhang, G.; et al. Using the Eco-Erosion Index to assess regional ecological stress due to urbanization-A case study in the Yangtze River Delta urban agglomeration. Ecol. Indic. 2020, 111, 106028. [CrossRef]

50. Zhou, F.; Hu, J. Annual Report on Resources and Environment of Shanghai (2020); Social Sciences Academic Press(CHINA): Shanghai, China, 2020.

51. Cai, W.; Wu, T.; Jiang, W.; Peng, W.; Cai, Y. Integrating Ecosystem Services Supply-Demand and Spatial Relationships for Intercity Cooperation: A Case Study of the Yangtze River Delta. Sustainability 2020, 12, 4131. [CrossRef]

52. Nedkov, S.; Burkhard, B. Flood regulating ecosystem services-Mapping supply and demand, in the Etropole municipality, Bulgaria. Ecol. Indic. 2012, 21, 67-79. [CrossRef] 
53. Kandulu, J.M.; MacDonald, D.H.; Dandy, G.; Marchi, A. Ecosystem Service Impacts of Urban Water Supply and Demand Management. Water Resour. Manag. 2017, 31, 4785-4799. [CrossRef]

54. Parsa, V.A.; Salehi, E.; Yavari, A.R.; van Bodegom, P.M. An improved method for assessing mismatches between supply and demand in urban regulating ecosystem services: A case study in Tabriz, Iran. PLoS ONE 2019, 14, e0220750.

55. Li, J.H.; Fang, W.; Wang, T.; Qureshi, S.; Alatalo, J.M.; Bai, Y. Correlations between Socioeconomic Drivers and Indicators of Urban Expansion: Evidence from the Heavily Urbanised Shanghai Metropolitan Area, China. Sustainability 2017, 9, 1199. [CrossRef]

56. Shu, H.; Xiong, P.-p. Reallocation planning of urban industrial land for structure optimization and emission reduction: A practical analysis of urban agglomeration in China's Yangtze River Delta. Land Use Policy 2019, 81, 604-623. [CrossRef]

57. Peng, W.T.; Liu, W.Q.; Cai, W.B.; Wang, X.; Huang, Z.; Wu, C.Z. Evaluation of ecosystem cultural services of urban protected areas based on public participation GIS (PPGIS): A case study of Gongqing Forest Park in Shanghai, China. Ying Yong Sheng Tai Xue Bao J. Appl. Ecol. 2019, 30, 439-448.

58. He, S.; Su, Y.; Shahtahmassebi, A.R.; Huang, L.; Zhou, M.; Gan, M.; Deng, J.; Zhao, G.; Wang, K. Assessing and mapping cultural ecosystem services supply, demand and flow of farmlands in the Hangzhou metropolitan area, China. Sci. Total Environ. 2019, 692, 756-768. [CrossRef] [PubMed]

59. DPYRDUA, Development Plan of the Yangtze River Delta Urban Agglomeration (2016-2030). State Council of the PRC. 2016. Available online: https:/ / www.ndrc.gov.cn/xxgk/zcfb/ghwb/201606/W020190905497826154295.pdf (accessed on 29 July 2021).

60. RPYRDR, Regional Plan for the Yangtze River Delta Region (2009-2020). China's State Council and the National Development and Reform Commission (NDRC). 2010. Available online: https://wenku.baidu.com/view/4ae7c62c2af90242a895e5ee.html (accessed on 29 July 2021).

61. Xu, W.; Tian, Y.; Zhang, Y.; Zhen, J.; Fang, W.; Lv, H.; Yang, X.; Wan, R.; Zhao, T.; Shi, P. Comprehensive Ecological Risk Prevention: Natural Disaster Factors and Risk Assessment in the Yangtze River Delta Region; Science Press: Beijing, China, $2014 ;$ Volume 1. (In Chinese)

62. TBA. The Health Status Report of Taihu Lake. In Resources. Available online: http://www.tba.gov.cn/slbthlyglj/thjkzkbg/ content/slth1_5d691c607c6c4b6fae10962853b6b9de.html (accessed on 29 July 2021).

63. TBA. Annual Report of Flood Control and Typhoon Prevention in Taihu Lake Basin. In Resources. Available online: http: / / www.tba.gov.cn/slbthlyglj/fxkhnb/content/slth1_1ac642f144de41c39c51906301205d0a.html (accessed on 29 July 2021).

64. Shou, F.; Li, Z.; Huang, L.; Huang, S.; Yan, L. Spatial differentiation and ecological patterns of urban agglomeration based on evaluations of supply and demand of ecosystem services: A case study on the Yangtze River Delta. Acta Ecol. Sin. 2020, 40, 2813-2826.

65. Gao, Y.; Li, J.; Liu, R.; Wang, Z.; Wang, H.; Liu, Y. Temporal and spatial evolution of greenspace system and evaluation of ecosystem services in the core area of the Yangtze River Delta. Chin. J. Ecol. 2020, 39, 956-968.

66. Li, Z.; Sun, Z.; Tian, Y.; Zhong, J.; Yang, W. Impact of Land Use/Cover Change on Yangtze River Delta Urban Agglomeration Ecosystem Services Value: Temporal-Spatial Patterns and Cold/Hot Spots Ecosystem Services Value Change Brought by Urbanization. Int. J. Environ. Res. Public Health 2019, 16, 123. [CrossRef] [PubMed]

67. Gopalakrishnan, V.; Bakshi, B.R.; Ziv, G. Assessing the capacity of local ecosystems to meet industrial demand for ecosystem services. AIChE J. 2016, 62, 3319-3333. [CrossRef]

68. Jie, X.; Yu, X.; Na, L.; Hao, W. Spatial and temporal patterns of supply and demand balance of water supply services in the Dongjiang Lake Basin and its beneficiary areas. J. Resour. Ecol. 2015, 6, 386-396. [CrossRef]

69. Wu, W. On the Population Distribution and Changes of YRD Region from 2000 2010 (in Chinese, English Abstract). Northwest Popul. 2017, 38, 39-53.

70. Shira, D.; Devonshire-Ellis, C.; Jones, S.L.; Ku, E. The Yangtze River Delta: Business Guide to the Shanghai Region; Springer Science \& Business Media: Berlin, Germany, 2012.

71. Li, B.; Chen, D.; Wu, S.; Zhou, S.; Wang, T.; Chen, H. Spatio-temporal assessment of urbanization impacts on ecosystem services: Case study of Nanjing City, China. Ecol. Indic. 2016, 71, 416-427. [CrossRef]

72. Tao, Q.; Tao, Y.; Ou, W. Spatial variation of supply and demand relationships of recreational service in the Yangtze River Delta. Acta Ecol. Sin. 2021, 41, 1777-1785.

73. Cai, H.; Ma, K.; Luo, Y. Geographical Modeling of Spatial Interaction between Built-Up Land Sprawl and Cultivated Landscape Eco-Security under Urbanization Gradient. Sustainability 2019, 11, 19. [CrossRef]

74. Chen, W.; Chi, G.; Li, J. The spatial aspect of ecosystem services balance and its determinants. Land Use Policy 2020, 90, 104263. [CrossRef]

75. Wang, H.; Wang, C.; Wu, W.; Mo, Z.; Wang, Z. Persistent organic pollutants in water and surface sediments of Taihu Lake, China and risk assessment. Chemosphere 2003, 50, 557-562. [CrossRef]

76. Xu, X.; Yang, G.; Tan, Y.; Zhuang, Q.; Li, H.; Wan, R.; Su, W.; Zhang, J. Ecological risk assessment of ecosystem services in the Taihu Lake Basin of China from 1985 to 2020. Sci. Total Environ. 2016, 554, 7-16. [CrossRef] [PubMed]

77. Hou, Y.; Zhou, S.; Burkhard, B.; Muller, F. Socioeconomic influences on biodiversity, ecosystem services and human well-being: A quantitative application of the DPSIR model in Jiangsu, China. Sci. Total Environ. 2014, 490, 1012-1028. [CrossRef] [PubMed]

78. Xu, X.; Yang, G.; Tan, Y.; Liu, J.; Hu, H. Ecosystem services trade-offs and determinants in China's Yangtze River Economic Belt from 2000 to 2015. Sci. Total Environ. 2018, 634, 1601-1614. [CrossRef] 
79. Calzolari, C.; Ungaro, F.; Filippi, N.; Guermandi, M.; Malucelli, F.; Marchi, N.; Staffilani, F.; Tarocco, P. A methodological framework to assess the multiple contributions of soils to ecosystem services delivery at regional scale. Geoderma 2016, 261, 190-203. [CrossRef]

80. Lorilla, R.S.; Kalogirou, S.; Poirazidis, K.; Kefalas, G. Identifying spatial mismatches between the supply and demand of ecosystem services to achieve a sustainable management regime in the Ionian Islands (Western Greece). Land Use Policy $2019,88,104171$. [CrossRef]

81. Hou, Y.; Burkhard, B.; Muller, F. Uncertainties in landscape analysis and ecosystem service assessment. J. Environ. Manag. 2013, 127, S117-S131. [CrossRef] [PubMed] 